\title{
GOLD NANOPARTICLE TRANSPORT IN MULTILAYERED CELL CULTURES
}

\author{
By: \\ Darren Yohan \\ B.Sc. Ryerson University, 2013 \\ Toronto, Canada \\ A thesis \\ presented to Ryerson University \\ in partial fulfillment of the \\ requirements for the degree of \\ Master of Science \\ in the Program of \\ Biomedical Physics \\ Toronto, Ontario, Canada, 2015 \\ (C) Darren Yohan 2015
}




\section{Author's Declaration}

I hereby declare that I am the sole author of this thesis. This is a true copy of the thesis, including any required final revisions as accepted by my examiners.

I authorize Ryerson University to lend this thesis to other institutions or individuals for the purpose of scholarly research.

I further authorize Ryerson University to reproduce this thesis by photocopying or by other means, in total or in part, at the request of other institutions or individuals for the purpose of scholarly research.

I understand that this thesis may be made electronically available to the public.

Darren Yohan 


\title{
Abstract
}

\section{Gold Nanoparticle Transport in Multilayered Cell Cultures}

\author{
Darren Yohan \\ Master of Science \\ Biomedical Physics, 2015 \\ Ryerson University
}

Gold nanoparticles (GNPs) possess a number of useful characteristics that have catapulted them into the mainstream of cancer research. Their optical properties enable them to be used in photodynamic and photothermal therapy as well as contrast agents in photoacoustic imaging. In addition, the ability to bind ligands to the GNP surface has made them valuable bio-markeraware drug carriers. But the effectiveness of any cancer fighting tool relies on homogenous distribution and penetration throughout the tumor, and the uptake and transport dynamics of GNPs has previously been held to monolayer cell models. In this work, multicellular layers (MCLs) are used as a solid tumor model to measure the penetration and uptake of GNPs in tumor tissue. MCLs offer a unique way to bridge the gap between in vitro single-layer cell models and the in vivo tumor. The effects of increased cell-to-cell connections, extracellular matrix and tumor characteristics are investigated to deliver new insights into the transport of GNPs in tissue. 


\section{Acknowledgements}

I wish to thank my committee members, Dr. Lee Chin and Dr. Carl Kumaradas. They pushed me to be better and helped me find new ways to improve my research. Their demand for better results and more thorough discussion has helped me greatly in this work and I will forever be indebted to them for the lessons they have taught me.

It is impossible to imagine how this work would have been completed without the vision and inspiration of my supervisor Dr. Devika Chithrani. Her tireless efforts to not only motivate but also to educate her students is nothing short of remarkable. Her lessons and attitudes toward research are something I will carry with me for the rest of my life.

Last but not least I would like to express my appreciation to Celina Yang and Charmainne Cruje who worked alongside me and were always there to offer their expertise and in many cases their sympathies. I would also like to thank Arthur Worthington and Elizabeth Berndl without whom this project would never have gotten off the ground. I also wish to thank Tess Sy and Adriana Gaertner for their overwhelming support and guidance.

And of course I would like to thank the students, staff and faculty at Ryerson who never shied away from questions and sought to offer any help they could. 


\section{Table of Contents}

Author's Declaration $\quad$ ii

Abstract iii

Acknowledgements $\quad$ iv

Table of Contents $\quad \mathrm{V}$

List of Figures vi

Symbols and Abbreviations $\quad$ viii

\section{Introduction}

1.1.0 Motivations 1

1.1.1 Considerations for Cell Lines 3

1.1.2 The Tumor Environment 4

1.1.3 The Extracellular Matrix 6

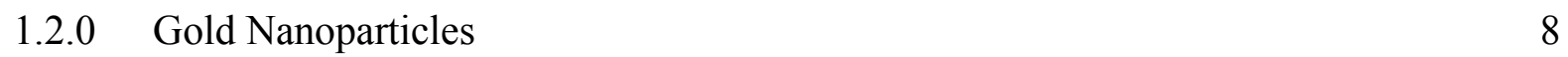

1.2.1 Gold Nanoparticle Uptake in Monolayer Cultures and Solid Tumor 11 Models

$\begin{array}{lll}\text { 1.3.0 } & \text { Multilayered Cell Cultures } & 14\end{array}$

1.4.0 Hypothesis and Specific Objectives 16

Elucidating the Uptake and Distribution of Nanoparticles in Solid Tumors via a Multilayered Cell Culture Model

2.0.0 Abstract 32

2.0.1 Introduction $\quad 33$

2.0.2 Materials and Methods $\quad 37$

2.0.3 Results and Discussion $\quad 43$

$\begin{array}{lll}2.0 .4 & \text { Conclusions } & 49\end{array}$

\section{Multilayer Cell Culture Uptake of 50 nm Gold Nanoparticles}

3.0.0 Abstract $\quad 56$

3.1.0 Size Dependence of Gold Nanoparticle Uptake $\quad 57$

3.1.1 Size Dependence at the Multilayer Level 59

$\begin{array}{lll}\text { 3.1.2 Conclusions and Future Work } & 64\end{array}$ 


\section{List of Figures}

\section{Introduction}

Figure 1: Schematic showing the milk ducts connecting the lobules to the nipple.

Figure 2: MCF-7 and MDA-MB-231 cells grown at the monolayer level and incubated with 20 nm GNPs.

Figure 3: GNP Synthesis via the Turkevich method. In Step 1, chloroauric acid is added to distilled water and brought to a boil. In step 2, sodium citrate is added to the mixture and acts as both a reducing and capping agent. After several minutes, the mixture changes color indicating the formation of GNPs.

Figure 4: Basic schematic of MLC growth. Monolayer cells are cultured and then seeded onto a semi-permeable membrane. The MLC structure then grows upward forming layers of cells in the insert as opposed to spreading out as cells do in monolayer cultures.

\section{Elucidating the Uptake and Distribution of Nanoparticles in Solid Tumors via a Multilayered Cell Culture Model}

Figure 1: Use of MCL cell model to understand the NP transport through the tumor tissue. A, Transport of GNPs through the blood vessels and enters tumor vasculature. The interface between tumor vasculature and tumor tissue is highlighted with a yellow box. B, GNPs escape the tumor vasculature through leaky endothelial cells (1) and enter tumor cells through ECM. C, Description shown in B is modeled using proposed MCL cell model. MCL act as a tumor tissue being fed by tissue culture media containing GNPs (2).

Figure 2: Growth of MCLs. A, Diagrammatic representation of the apparatus used to culture MCLs. Tissue culture inserts are held suspended in stirred media (top left). The set-up was placed in a humidified incubator with $5 \% \mathrm{O}_{2}, 5 \% \mathrm{CO}_{2}, 95 \% \mathrm{~N}_{2}$. After the growth, GNPs were introduced into the media to investigate the NP transport through tissue (top right). B, A crosssection of an unstained MCF-7 tissue. C, A cross-section of a MCF-7 tissue stained with eosin to map the ECM. Areas marked in green belong to ECM while the unstained regions represent cells.

Figure 3: Visualization and mapping of GNPs in cells using CytoViva hyperspectral Imaging (HSI) optical microscopy. A,The unmapped dark field HSI image with GNPs visible as bright spots. B, The result of a spectral angle mapping on the HSI image. GNPs have been labeled red as a result of matching spectra from individual pixels. C, GNP spectra from few NP clusters localized within cells and the reference spectra (inset) used to create the spectral angle map in B.

Figure 4: Characterization of monolayer and multilayer cell structures. A-B, Comparison of growth curves for the MDA-MB-231 and MCF-7 cell lines at monolayer and multilayer level, 
respectively. C-D,A monolayer and multilayer cross-section of MDA-MB-231 cells stained with eosin to highlight the ECM, respectively. Cell population doubling times for MCF-7 and MDAMB-231 monolayer cell cultures were 38.83 and $37.10 \mathrm{hrs}$, respectively. Cell population doubling times for MCF-7 and MDA-MB-231 multilayer cell cultures were 48.36 and 51.07 hrs, respectively. Error bars represent the standard deviation and $\mathrm{n}=3$.

Figure 5: GNP uptake in monolayer cell models. A, NP uptake per cell as a function of cell density. B, Total uptake of NPs as a function of cell density. C and D show samples of H\&E stained monolayer MDA-MB-231 and MCF-7 cells with GNPs present mostly in the cells. Error bars represent the standard deviation and $\mathrm{n}=3$.

Figure 6: Differences in extracellular matrix (ECM) in MDA-MB-231 and MCF-7 tissue structures. A and C, MCL tissue of MCF-7 cells at 10x and 60x magnification, respectively. B and D, MCL tissue of MDA-MB-231 cells at 10x and 60x, respectively. Differences in the ECM structure can be seen at both magnifications. MCF-7 tissue had a much more organized ECM structure while MDA-MB-231 tissue has a disorganized ECM structure which allowed easy penetration of molecules into deeper tissues.

Figure 7: GNP uptake in multilayer cell models. A, Accumulation of GNPs in tissue as a function of its thickness. NPs were able to penetrate deep into tissue in MDA-MB-231 tissue due to the break down in ECM matrix. In MCF-7 tissue, most NPs were localized at the top layers and properly organized ECM acted as a barrier for their transport deep into the tissue. B, The normalized percent increase in GNP uptake as a function of tissue thickness. Error bars represent the standard deviation and $\mathrm{n}=3$.

Figure 8: Mapping of NP transport through different layers of a thicker tissue. A, A schematic depicting the multiple layers of a tissue cross-section. B, Accumulation of NPs in different layers of tissue. C-D, Mapping of the NP distribution in MDA-MB-231 and MCF-7 tissue (with GNPs labelled in red), respectively. E-F,A sample of reflectance spectra of GNPs localized in ECM and cells, respectively.Error bars represent the standard deviation and $n=3$.

\section{Multilayer Cell Culture Uptake of $50 \mathrm{~nm}$ Gold Nanoparticles}

Figure 1: Thematic figure representing the comparison of GNP uptake in monolayer (left) and multilayer cell cultures (right). GNPs spread evenly regardless of size in monolayer cultures and $50 \mathrm{~nm}$ GNPs have a higher relative uptake per cell. In the MLC $50 \mathrm{~nm}$ GNPs display poorer accumulation and penetration as they wrestle with the prohibitive effects of the ECM.

Figure 2: Accumulation of GNPs as a function of tissue thickness for $20 \mathrm{~nm}$ GNPs (left) and 50 nm GNPs (right).

Figure 3: Penetration of GNPs calculated by taking the difference in accumulation on consecutive days of growth. The left group shows the penetration of $20 \mathrm{~nm}$ GNPs as a function of MCL layer and the right shows the penetration of $50 \mathrm{~nm}$ GNPs as a function of layer.

Figure 4: Single day GNP uptake per cell for the monolayer and multilayer cultures across both cell lines for the 20 and $50 \mathrm{~nm}$ GNPs. 


\section{Abbreviations}

GNPs - Gold Nanoparticles

MCL - Multicellular layers; also seen as MCC (multicellular cultures) or MLC (multilayered cell culture) in other works

ECM - Extracellular matrix

ICP-AES - Inductively Coupled Plasma Atomic Emission Spectroscopy

VEGF - Vascular Endothelial Growth Factor

SPR - Surface Plasmon Resonance

RME - Receptor-mediated Endocytosis

$\mathbf{n m}-$ Nanometer or $1 \times 10^{-9} \mathrm{~m}$

PBS - Phosphate Buffered Saline

SAM - Spectral Angle Mapping

FBS - Fetal Bovine Serum

DLS - Dynamic Light Scattering

RT - Radiation Therapy

PTT - Photothermal Therapy

PDT - Photodynamic Therapy 


\section{Introduction}

\subsection{0 - Motivations}

Cancer is a term with a broad definition. It encompasses a class of diseases that involve excessive and abnormal cell growth leading to the appearance of tumors. Many of these growths can begin in one tissue in the body and quickly spread to other organs in a process called metastasis. The local spread of a cancer throughout one organ is termed invasion and many cancers are characterized by their invasiveness or ability to spread quickly throughout the originating organ. As cancer can arise in a number of different tissues, each with different metastatic and invasive qualities, there are over 100 different cancers that have been detected in humans and each are named for the cell-type in which the tumor originated(1-3).

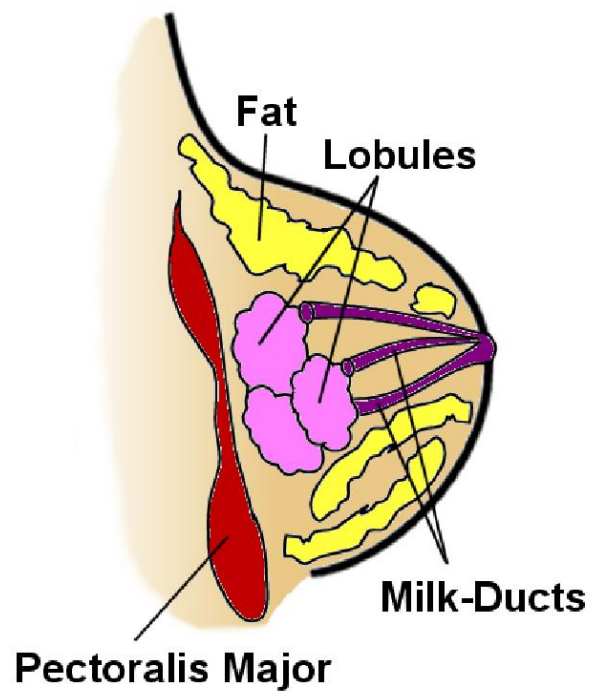

Figure 1: Schematic showing the milk ducts connecting the lobules to the nipple. 
Cancers originating in epithelial cells are referred to as carcinomas. These cancers are some of the most common types and include breast, lung, prostate and colon cancers. About a quarter of all cancer occurrences in women are breast cancers and it was reported that in 2012, over 522,000 deaths were attributed to breast cancer worldwide. The most common type of malignant breast cancer is the invasive ductal carcinoma which makes up roughly $80 \%$ of all breast cancer cases(1). This type of cancer describes a species of cells that invades the breast tissue (invasive), originates in the milk ducts that carry milk to the nipple from the lobule (ductal, see Figure 1) and were formed from normal epithelial cells in breast tissue (carcinoma).

Gold nanoparticles (GNPs), particles in the size range from 1-100 nm, have recently been used to target these cancer cells in a variety of therapies(4-42). However much of what is known about how GNPs interact with these types of cancer cells is derived from monolayer cell cultures that ultimately fall short of representing the in vivo tumor environment. Because of this, the effectiveness of several GNP therapies and systems are sometimes overstated and in vivo trials fall short of expectations(11,43-46). In this work, a new multilayer cell culture is used in an attempt to bridge the gap between the in vitro model and in vivo realities. 


\subsection{1 - Considerations for Cell Lines}

In this work, two cell lines: MDA-MB-231 and MCF-7 were chosen as a model tumor type. These cell lines were chosen for their similarities and one key difference. Both cell lines are invasive ductal carcinomas and thus represent one of the most commonly encountered types of cancers. This also means that both cell lines are derived from the same tissue which helps limit the potential variations between tissue types. In addition, both cell lines have comparable doubling times and sizes. The MDA-MB-231 cell line however has been identified as being far more aggressive and invasive than the MCF-7 cell line(47-53). This key difference affects the makeup and proliferation of not only the cells themselves but also the extracellular matrix (ECM) that surrounds them. The importance of the ECM and its makeup will be discussed in section 1.1.3.

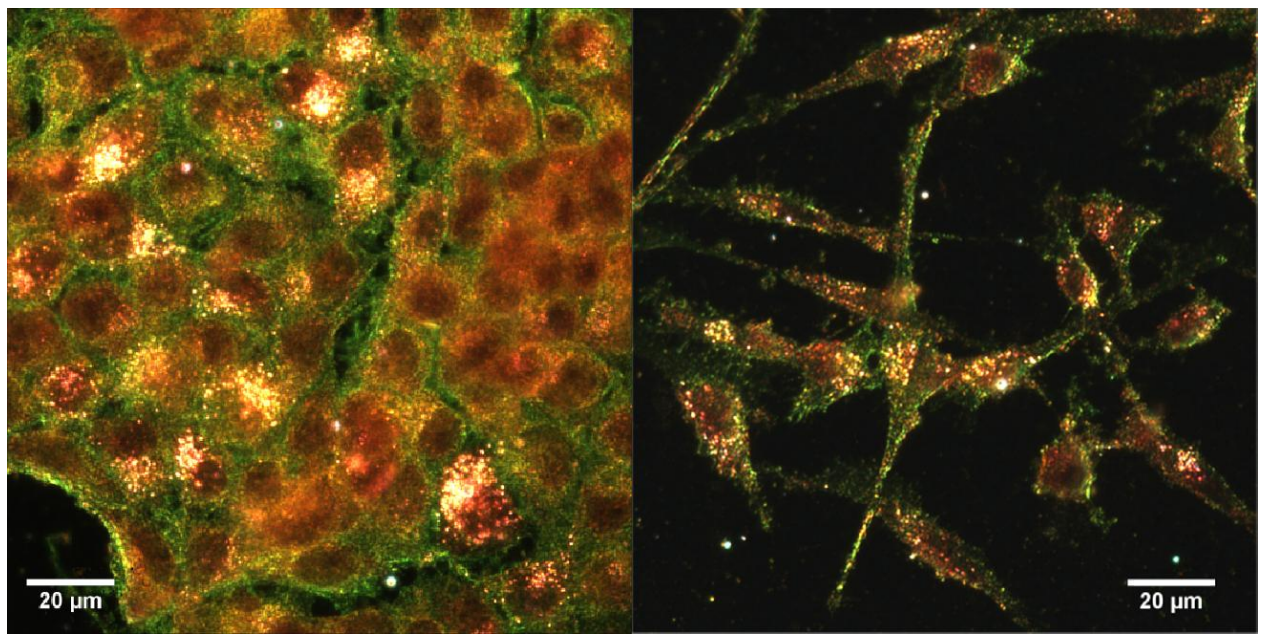

Figure 2: MCF-7 and MDA-MB-231 cells grown at the monolayer level and incubated with 20 nm GNPs. 


\subsection{2 - The Tumor Environment}

The tumor environment consists of abnormal cells as well as their surrounding ECM, blood vessels, immune cells, fibroblasts and signaling molecules $(54,55)$. Tumor cells can readily activate a variety of pathways by communicating with their surrounding environment. One of the most important of these pathways is that of tumor angiogenesis. Cancer cells require a supply of nutrients and oxygen in order to maintain the excessive proliferation rate that is a hallmark of the disease. By secreting growth factors such as Vascular Endothelial Growth Factor (VEGF), tumors can promote the growth of blood vessels(25,54-58).

This increase in VEGF and other factors that promote the growth of blood vessels in tumors leads to a disorganized vasculature that differs greatly from that of normal tissue. Normal tissue consists of highly ordered, hierarchal vascular networks. This organized network is driven by metabolic demands and regulated by pro and anti-angiogenic molecular factors. Coupled with this vasculature is a lymphatic draining system that removes metabolic waste from the interstitium $(54,55,59)$. In tumors the aggressive expression of pro-angiogenic factors like VEGF leads to the development of immature, torturous and hyperpermeable blood vessels. Tumor vessels can lack smooth muscle cells and possess a discontinuous endothelial lining which leads to increased permeability. Blood vessel diameters and shapes are also found to be non-uniform in tumor tissue and abnormal bulges and blind ends can form. All of these effects can lead to regions of hypoxia and anoxia in tumor tissue which can give rise to resistance during radiation therapy. This leads to a drastic falloff in the ability of tumors to deliver nutrients and oxygen homogenously to all cells of the tumor while leaky, dilated lymphatic vessels hamper the removal of metabolic waste(55). 
It has been reported that in tumors, cells can appear further than $150 \mu \mathrm{m}$ from the nearest blood vessel(60). In such a case, any agents delivered to the tumor through the bloodstream will have to navigate the heterogeneous tumor environment without assistance from any vascular network to reach their target cells. The purpose of this work is to examine the penetration and transport of gold nanoparticles (GNPs) through such tissue. To model the tumor tissue, multilayered cell cultures (MLCs) were grown and GNPs of several sizes were incubated with samples of increasing thickness. The accumulation of GNPs in the MLC tissue was measured to determine the major factors affecting GNP transport through tumor tissue in the absence of vasculature. 


\subsection{3 - The Extracellular Matrix}

As cells grow they secrete proteins and molecules that form a structural and biological support network known as the extracellular matrix (ECM). Because different cells secrete different proteins with different functions, the composition and architecture of the ECM varies from one cell line to another. The ECM carries out a number of important functions and enables cell-tocell communication, cell adhesion and provides a rigid support structure that gives tissue its shape. This support structure also determines the permeability of tissue to molecules and other particles $(61,62)$.

In epithelial cells, the ECM combines the use of a highly organized collagen network, hyaluronic acid and a number of proteins to prohibit the passage of macromolecules through tissue.

Transport through the ECM is largely mediated via diffusion and thus the ECM is less permeable to particles of larger sizes as given by the stokes-Einstein equation:

$$
D=\frac{k_{b} T}{6 \pi \mu R_{h}}
$$

In the above equation $\mathrm{D}$ is the diffusion coefficient in $\mathrm{m} / \mathrm{s}$ (often $\mathrm{cm} / \mathrm{s}), \mathrm{k}_{\mathrm{b}}$ the Boltzmann consent, $\mathrm{T}$ the temperature in $\mathrm{K}, \mu$ the viscosity in $\mathrm{kg} / \mathrm{s} / \mathrm{m}$ and $\mathrm{R}_{\mathrm{h}}$ the hydrodynamic radius of the passing particle in $\mathrm{m}$.

Several studies have noted that the limiting effects of the ECM are tied to collagen content and the structural organization of the ECM itself and less so to the hyaluronic acid. Convection through the interstitial matrix, while an important part of interstitial fluid and particle movement, is limited by the hypertension found in the interstitium(63-66). Many anticancer agents such as liposomes and gene vectors are large molecules ranging in size from 90-300 nm. Nanoparticle 
agents being developed also vary greatly in size ranging from 2-200 $\mathrm{nm}(55,64-67)$. Thus diffusion through the interstitial matrix of the tumor presents a major barrier to the delivery of therapeutic agents and drugs.

Cancer cells have been shown to disrupt and change the composition and makeup of the ECM. Invasive species in particular have been shown to attack the collagen meshwork that provides the ECM with its ability to limit the flow of foreign particles through tissue $(49,50)$. The two cell lines used in this work are thus separated by the makeup and composition of their respective ECM. The measurements taken will establish what affect the ECM has on the transport of GNPs in tissue. 


\subsection{0 - Gold Nanoparticles}

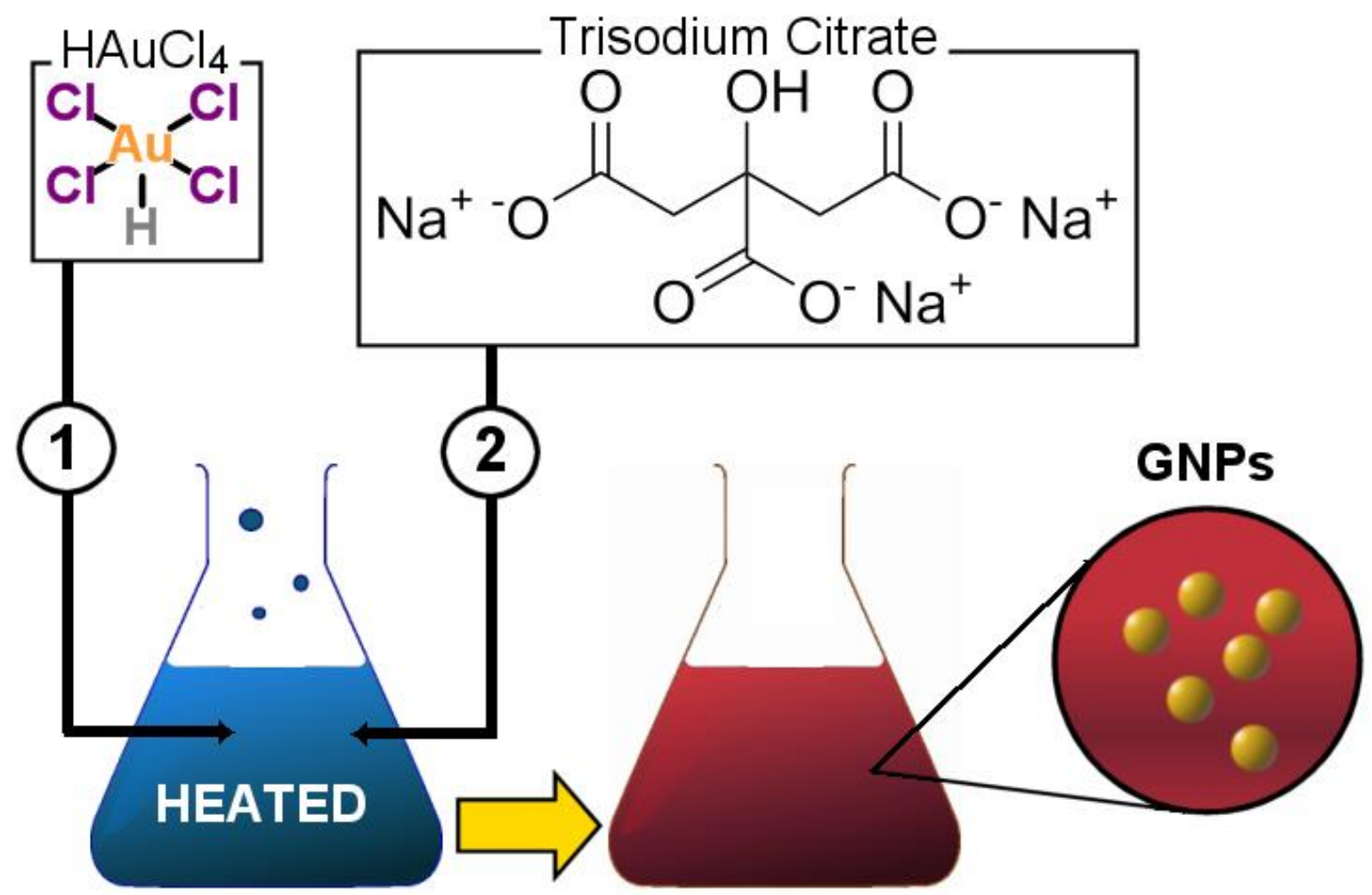

Figure 3: GNP Synthesis via the Turkevich method. In Step 1, chloroauric acid is added to distilled water and brought to a boil. In step 2, sodium citrate is added to the mixture and acts as both a reducing and capping agent. After several minutes, the mixture changes color indicating the formation of GNPs.

Gold nanoparticles (GNPs) consist of gold particles in the size range from 1-100 nm. This size range allows for particles that can potentially traverse both the cellular and nuclear membrane $(35,68)$. In recent years, GNPs and other nanoparticles have emerged as one of the most robust and flexible tools in cancer research. Their applications cover the full breadth of the clinical spectrum from enhancing diagnostic imaging(69) to photothermal(12,70-75) and photodynamic therapy(11,22,76-80), drug delivery $(6,8,12,43,77,81-85)$ and radiosensitization(21,23,26,38,39,86-88) owing to their high $\mathrm{Z}$ number. Each of these therapies 
places different requirements on the proximity of the GNPs to the target cells. Thus the design of GNP-ligand systems depends heavily on the planned treatment. As drug carriers, GNPs provide protection for $\mathrm{pH}$ sensitive drugs and can be functionalized with a variety of biological ligands to increase circulation time and cellular uptake $(6,8,82)$.

Many of the more interesting applications of GNPs stem from their unique optical properties which can be tuned for increased effectiveness $(19,30,89)$. For example, it was found that gold nanoshells exhibit flexible photo-absorption and scattering peaks that correspond with changes to the ratio of the shell's core to external radius. The peak photo-absorption band of gold nanorods is also tunable and is determined by the aspect ratio of the rods themselves. Many of these unique optical properties stem from the phenomenon of surface plasmon resonance (SPR). Conduction-band electrons can be made to oscillate by light incident on the surface of the particle. When the frequency of the incident light matches the frequency of the oscillation, the SPR effect is achieved. Because this frequency changes with the particle size, the absorption and scattering characteristics of the particles are highly determined by the size of the particles or as in the case with rods and shells, the interplay between the various dimensions of the particles $(5,14,19,24,30,72,90-94)$.

GNPs can also be functionalized by a variety of biological ligands. These ligands can be bound to the surface of GNPs by electrostatic attraction, hydrophobic interactions, and chemisorption or by a head group on the ligand. In particular, the thiol group has a natural affinity to gold and is a popular choice for binding ligands to the surface of GNPs. Biological ligands can provide GNPs with cell-specific targeting, increased uptake and even nuclear transport while maintaining biocompatibility(7-9,35,38,43,82,95-98). 
Gold nanospheres are also remarkably easy to synthesize. The most commonly used method for creating gold nanospheres is the Turkevitch method. In this method, chloroauric acid (HAuCl4) is brought to a boil and brought into contact with small amounts of sodium citrate. The citrate reduces the acid and also acts as a capping agent for the resulting spheres (Figure 3)(99). Later works showed that lowering the amount of sodium citrate produced spheres of increasing size with low polydispersity(100). GNPs can then be characterized either by UV spectrum analysis to determine their absorption peaks or by dynamic light scattering or transmission electron microscopy. 


\subsection{1 - Gold Nanoparticle Uptake in Monolayer Cultures and Solid Tumor Models}

GNPs were found to enter cells through receptor-mediated endocytosis (RME)(101). At the monolayer level, several studies have observed that GNPs exhibit a size-dependent uptake(102). This size-dependence is explained by the energy dynamics surrounding RME with $50 \mathrm{~nm}$ spheres showing a significantly higher uptake than either larger or smaller sizes(102,103). As particles interact with the surface of the cell, receptors are recruited and bound to the GNP in an exothermic process. This binding of receptors to the surface of the particle provides the cell with the energy required to begin the invagination process that will surround the particle and prepare it for entry into the cell. Smaller particles provide less surface area for receptors to bind and as a result offer less total energy for the invagination process. In larger sizes, the number of receptors required to surround the GNP is much higher and the limited number of receptors means that fewer large-sized particles can be taken up by the cell(104). As such there exists an optimal particle size that takes full advantage of both of these dynamics.

One possible explanation for this effect was presented by Zhang et. al who proposed a thermodynamic model that governed the energy interplay between cell receptors, ligands on the GNP surface, and the elastic deformation energy of the cell(105). The model supposes that each membrane-bound receptor on the surface of the cell has a cross-sectional area $\mathrm{A}_{0}$ such that the maximum possible number of receptors bound to the surface of a GNP with radius $\mathrm{R}$ is given by

$$
K=4 \pi R^{2} / A_{0}
$$

The binding of cell receptors to ligands on the GNP releases a chemical energy $\mu$ which is used to overcome the energy barrier posed by the elastic deformation energy of the cell membrane $\Gamma$ where $\Gamma$ is a function of $\kappa$, the bending rigidity of the cell membrane and $\sigma$ the membrane 
tension. In the case of small GNPs, the chemical energy released by the receptor-ligand binding $\mu$ is too small to overcome $\Gamma$ and thus small GNPs are incapable of entering a cell via endocytosis unless they are bundled together. This result is corroborated by Chithrani et. al who showed that $7 \mathrm{~nm}$ GNPs were only able to enter cells in cluster of $\sim 6$ GNPs(102). At larger particle sizes the GNPs compete for a finite number of receptors on the surface of the cell membrane and thus uptake suffers. While these receptors can diffuse along the cell membrane and are recycled after endocytosis, their limited number presents the major barrier to the uptake of larger sized GNPs $(104,105)$.

In tumor tissue however, the local environment is much more complex than in monolayer cell cultures. In recent studies, it was shown that NP penetration into the core of multicellular spheroids diminished as particle sizes increased from 20 to 40 to $100 \mathrm{~nm}$ with $<5 \%$ of the 100 $\mathrm{nm}$ NPs reaching the core of the spheroid compared to $57 \%$ and $32 \%$ of the 20 and $40 \mathrm{~nm}$ $\operatorname{NPs}(64)$.

Several factors have been proposed to explain the poor penetration and distribution of GNPs in solid tumors. These factors include the binding of GNPs to tumor tissue, increased interstitial fluid pressure, hindered diffusion due to cell packing and the $\operatorname{ECM}(56,61,62,106,107)$. It was shown however that the binding of GNPs to tumor tissue can be reduced by coating the GNPs in polyethylene glycol(108). Furthermore, the elimination of the pressure gradient in solid tumors yielded only minimal gains in macromolecule delivery(109) which suggests that cell packing and the ECM are major factors in the differences between monolayer and solid tumor penetration dynamics $(55,62)$. In this work, the importance of the ECM will be outlined as GNPs will no longer have direct access to cells but will instead be made to penetrate through layers of cells and ECM in the tumor tissue. To accomplish this, a much more complex cell culture is required. In 
this work, multilayered cell cultures were produced to model the layers of cells and ECM found in tumor tissue and these cultures are discussed in the next section. 


\subsection{0 - Multilayered Cell Cultures}

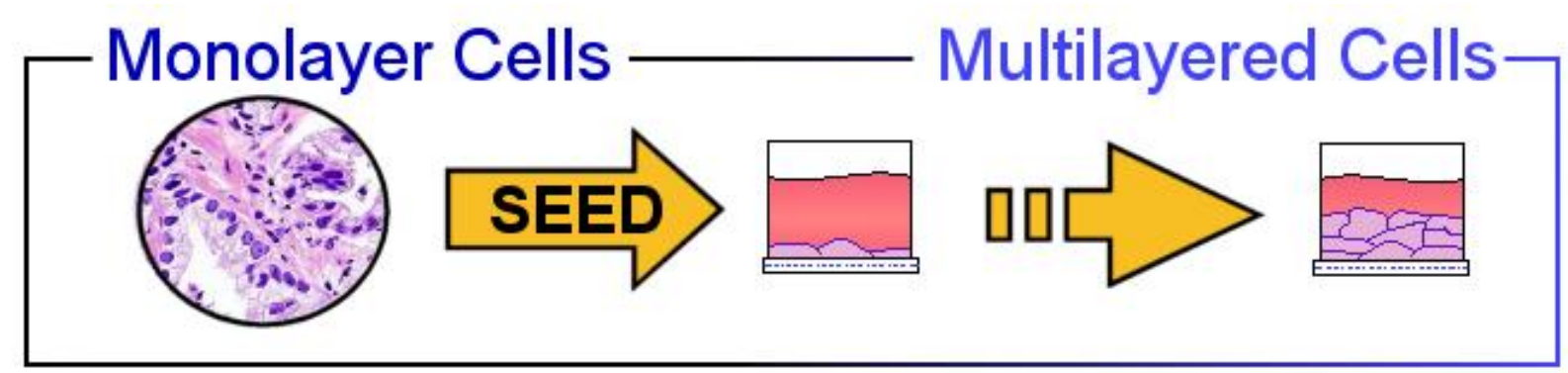

Figure 4: Basic schematic of MCL growth. Monolayer cells are cultured and then seeded onto a semi-permeable membrane. The MCL structure then grows upward forming layers of cells in the insert as opposed to spreading out as cells do in monolayer cultures.

To better model the tumor environment, cells were cultured on a semi-permeable membrane as described by Minchinton et. al(110). The multilayered cell culture (MCL or MLC in other works) develops into a thick mat of cells that acts as a barrier to the penetration of drugs and GNPs much in the same way as solid tumors and multicellular spheroids. They have been used to study the penetration of a variety of anticancer drugs as well as agents specifically targeted to hypoxic and nutrient deprived cells where penetration is of the utmost importance(59). Previous work using MCLs demonstrated the development of hypoxia and necrosis in MCLs greater than $150 \mu \mathrm{m}$ thick. The appearance of necrosis and hypoxia at $150 \mu \mathrm{m}$ of tissue thickness presents an upward bound on the tissue sizes considered in this study(60,111-115). The effects of hypoxia and necrosis on the transport of GNPs was shown recently to be quite complex(116) and will be pursued at the multilayer level in future works.

The geometry of the MLC also sets it apart from other 3D cell cultures like the multicellular spheroid. In the spheroid geometry, drugs and agents pass radially inwards from the edges of the 
spheroid. This geometry is often the reverse of in vivo physiology and makes it difficult to ascertain the penetration of drugs in a solid tumor $(59,110,115)$. The MCL provides a top-down or side-to-side geometry and better mimics the distribution of agents out of a blood vessel and down into tissue. By growing MCLs and harvesting them in succession, a measure of penetration as a function of tissue thickness can be observed by taking the difference in accumulation on consecutive days of growth. In this way the penetration of GNPs in tumors of varying sizes can be determined. The limiting effects of the ECM, the cell layers and the GNP transport mechanisms on the penetration of GNPs in tumor tissue can all be measured using the MCL model. While in vivo tumors offer the most clinically relevant tool for determining the spatial distribution and penetration of GNPs, the complex biological factors present prohibit a focused analysis of the individual components that contribute to the transport of GNPs and other agents $(55,65,67)$. As such models such as the MCL and the multicellular spheroid are valuable tools that can lead to the improved design of anticancer agents including NP-based systems. 


\subsection{0 - Hypothesis and Specific Objectives}

This study rests on the hypothesis that the role of the ECM in mediating the transport of GNPs is a significant one. To test this hypothesis, $20 \mathrm{~nm}$ GNPs were incubated both in monolayer cultures and in multilayered cell cultures using both the MDA-MB-231 and MCF-7 cell lines.

The specific objectives are:

- To observe the structural difference in ECM makeup between the MDA-MB-231 and MCF-7 cell lines via dark-field microscopy

- To provide a quantitative measure of GNP penetration in multilayered cell cultures

- To compare the accumulation of GNPs in multilayered cell cultures in two cell lines with differing ECMs 


\section{References}

1. de Martel, C., Ferlay, J., Franceschi, S., Vignat, J., Bray, F., Forman, D. and Plummer, M. (2008) Global burden of cancers attributable to infections in 2008: a review and synthetic analysis. The Lancet Oncology, 13, 607-615.

2. Bhatia, S., Frangioni, J.V., Hoffman, R.M., Iafrate, A.J. and Polyak, K. (2012) The challenges posed by cancer heterogeneity. Nat Biotech, 30, 604-610.

3. Ferrari, M. (2005) Cancer nanotechnology: opportunities and challenges. Nat. Rev. Cancer, 5, 161-171.

4. Alkilany, A.M., Frey, R.L., Ferry, J.L. and Murphy, C.J. (2008) Gold nanorods as nanoadmicelles: 1-naphthol partitioning into a nanorod-bound surfactant bilayer. Langmuir : the ACS journal of surfaces and colloids, 24, 10235-10239.

5. Ambrosi, A., Airo, F. and Merkoci, A. (2010) Enhanced gold nanoparticle based ELISA for a breast cancer biomarker. Analytical Chemistry, 82, 1151-1156.

6. Bergen, J.M., van Recum, H.A., Goodman, T.T., Massey, A.P. and Pun, S.H. (2006) Gold Nanoparticles as a Versatile Platform for Optimizing Physicochemical Parameters for Targeted Drug Delivery. Macromol Biosci, 6, 506-516.

7. Bindhani, B.K., Parida, U.K., Biswal, S.K., Panigrahi, A.K. and Nayak, P.L. (2013) Gold Nanoparticles and Their Biomedical Applications. Rev. Nanosci. Nanotechnol., 2, 247260.

8. Brown, S.D., Nativo, P., Smith, J.A., Stirling, D., Edwards, P.R., Venugopal, B., Flint, D.J., Plumb, J.A., Graham, D. and Wheate, N.J. (2010) Gold Nanoparticles for the Improved Anticancer Drug Delivery of the Active Component of Oxaliplatin. J. Am. Chem. Soc., 132, 4678-4684. 
9. Cai, W., Gao, T., Hong, H. and Sun, J. (2008) Applications of gold nanoparticles in cancer nanotechnology. Nanotechnology: Science and Applications, 1, 17-32.

10. Chithrani, B.D., Jelveh, S., Jalali, F., Van Prooijen, M., Allen, C., Bristow, R.G., Hill, R.P. and Jaffray, D.A. (2010) Gold Nanoparticles as a Radiation Sensitizer in Cancer Therapy. Radiat. Res., 173, 719-728.

11. Chouikrat, R., Seve, A., Vanderesse, R., Benachour, H., Barberi-Heyob, M., Richeter, S., Raehm, L., Durand, J.O., Verelst, M. and Frochot, C. (2012) Non polymeric nanoparticles for photodynamic therapy applications: recent developments. Current medicinal chemistry, 19, 781-792.

12. Cobley, C.M., Au, L., Chen, J. and Xia, Y. (2010) Targeting gold nanocages to cancer cells for photothermal destruction and drug delivery. Expert opinion on drug delivery, 7, 577-587.

13. Craig, G.E., Brown, S.D., Lamprou, D.A., Graham, D. and Wheate, N.J. (2012) Cisplatin-Tethered Gold Nanoparticles That Exhibit Enhanced Reproducibility, Drug Loading, and Stability: a Step Closer to Pharmaceutical Approval? Inorg. Chem., 51, 3490-3497.

14. Dykman, L. and Khlebtsov, N. (2012) Gold nanoparticles in biomedical applications: recent advances and perspectives. Chemical Society Reviews, 41, 2256-2282.

15. Ghosh, P.S., Kim, C.K., Han, G., Forbes, N.S. and Rotello, V.M. (2008) Efficient Gene Delivery Vectors by Tuning the Surface Charge Density of Amino Acid-Functionalized Gold Nanoparticles. ACS Nano, 2, 2213-2218.

16. Hainfeld, J.F., Dilmanian, F.A., Slatkin, D.N. and Smilowitz, H.M. (2008) Radiotherapy enhancement with gold nanoparticles. J. Pharm. Pharmacol., 60, 977-985. 
17. Hainfeld, J.F., Slatkin, D.N., Focella, T.M. and Smilowitz, H.M. (2006) Gold nanoparticles: a new X-ray contrast agent. British Journal of Radiology, 79, 248-253.

18. Hainfeld, J.F., Slatkin, D.N. and Smilowitz, H.M. (2004) The use of gold nanoparticles to enhance radiotherapy in mice. Physics in Medicine and Biology, 49, N309.

19. Huang, X. and El-Sayed, M. (2010) Gold nanoparticles: Optical properties and implementations in cancer diagnosis and photothermal therapy. Journal of Advanced Research, 1, 13-28.

20. Huang, X., Jain, P.K., El-Sayed, I.H. and El-Sayed, M.A. (2007) Gold nanoparticles: interesting optical properties and recent applications in cancer diagnostics and therapy. Nanomedicine (London, England), 2, 681-693.

21. Jain, S., Coulter, J.A., Hounsell, A.R., Butterworth, K.T., McMahon, S.J., Hyland, W.B., Muir, M.F., Dickson, G.R., Prise, K.M., Currell, F.J. et al. (2011) Cell-Specific Radiosensitization by Gold Nanoparticles at Megavoltage Radiation Energies. Int J Rad Oncol Biol Phys, 79, 531-539.

22. Ju, H., Roy, R.A. and Murray, T.W. (2013) Gold nanoparticle targeted photoacoustic cavitation for potential deep tissue imaging and therapy. Biomedical Optics Express, $\mathbf{4}$, $66-76$.

23. Kaur, H., Avasthi, D.K., Pujari, G. and Sarma, A. (2013) Radiosensitizing effect of gold nanoparticles in carbon ion irradiation of human cervical cancer cells. AIP Conference Proceedings, 1530, 205-210.

24. Loo, C., Lowery, A., Halas, N., West, J. and Drezek, R. (2005) Immunotargeted nanoshells for integrated cancer imaging and therapy. Nano letters, 5, 709-711. 
25. Mukherjee, P., Bhattacharya, R., Wang, P., Wang, L., Basu, S., Nagy, J.A., Atala, A., Mukhopadhyay, D. and Soker, S. (2005) Antiangiogenic properties of gold nanoparticles. Clinical cancer research : an official journal of the American Association for Cancer Research, 11, 3530-3534.

26. Ngwa, W., Korideck, H., Kassis, A.I., Kumar, R., Sridhar, S., Makrigiorgos, G.M. and Cormack, R.A. (2013) In vitro radiosensitization by gold nanoparticles during continuous low-dose-rate gamma irradiation with I-125 brachytherapy seeds. Nanomedicine : nanotechnology, biology, and medicine, 9, 25-27.

27. Niidome, T., Nakashima, K., Takahashi, H. and Niidome, Y. (2004) Preparation of primary amine-modified gold nanoparticles and their transfection ability into cultivated cells. Chem. Commun., 1978-1979.

28. Paciotti, G.F., Kingston, D.G.I. and Tamarkin, L. (2006) Colloidal Gold Nanoparticles: A Novel Nanoparticle Platform for Developing Multifunctional Tumor-Targeted Drug Delivery Vectors. Drug Dev. Res., 67, 47-54.

29. Pan, Y., Leifert, A., Ruau, D., Neuss, S., Bornemann, J., Schmid, G., Brandau, W., Simon, U. and Jahnen-Dechent, W. (2009) Gold nanoparticles of diameter $1.4 \mathrm{~nm}$ trigger necrosis by oxidative stress and mitochondrial damage. Small (Weinheim an der Bergstrasse, Germany), 5, 2067-2076.

30. Park, J., Estrada, A., Sharp, K., Sang, K., Schwartz, J.A., Smith, D.K., Coleman, C., Payne, J.D., Korgel, B.A., Dunn, A.K. et al. (2008) Two-photon-induced photoluminescence imaging of tumors using near-infrared excited gold nanoshells. Optics express, 16, 1590-1599. 
31. Rahman, W.N., Bishara, N., Ackerly, T., He, C.F., Jackson, P., Wong, C., Davidson, R. and Geso, M. (2009) Enhancement of radiation effects by gold nanoparticles for superficial radiation therapy. Nanomedicine, 5, 136-142.

32. Rippel, R.A. and Seifalian, A.M. (2011) Gold revolution--gold nanoparticles for modern medicine and surgery. J Nanosci Nanotechnol., 11, 3740-3748.

33. Thakor, A.S., Jokerst, J., Zavaleta, C., Massoud, T.F. and Gambhir, S.S. (2011) Gold nanoparticles: a revival in precious metal administration to patients. Nano letters, $\mathbf{1 1}$, 4029-4036.

34. Xu, X., Han, M.S. and Mirkin, C.A. (2007) A gold-nanoparticle-based real-time colorimetric screening method for endonuclease activity and inhibition. Angewandte Chemie (International ed.in English), 46, 3468-3470.

35. Yang, C., Neshatian, M., Van Prooijen, M. and Chithrani, B.D. (2013) Enhanced cancer therapeutics using peptide-modified gold nanoparticles. ACS Nano, 14, 4813-4819.

36. Zhang, Q., Iwakuma, N., Sharma, P., Moudgil, B.M., Wu, C., McNeill, J., Jiang, H. and Grobmyer, S.R. (2009) Gold nanoparticles as a contrast agent for in vivo tumor imaging with photoacoustic tomography. Nanotechnol, 20, 395102.

37. Zhang, X., Xing, J.Z., Chen, J., Ko, L., Amanie, J., Gulavita, S., Pervez, N., Yee, D., Moore, R. and Roa, W. (2008) Enhanced radiation sensitivity in prostate cancer by goldnanoparticles. Clin. Invest. Med. Phys., 31, E160-E167.

38. Zhang, X.-D., Wu, D., Shen, X., Chen, J., Sun, Y.-M., Liu, P.-X. and Liang, X.-J. (2012) Size-dependent radiosensitization of PEG-coated gold nanoparticles for cancer radiation therapy. Biomaterials, 33, 6408-6419. 
39. Zheng, Y., Hunting, D.J., Ayottea, P. and Sanche, L. (2008) Radiosensitization of DNA by Gold Nanoparticles Irradiated with High-Energy Electrons. Radiat. Res., 169, 19-27.

40. Zheng, Y. and Sanche, L. (2009) Gold Nanoparticles Enhance DNA Damage Induced by Anticancer Drugs and Radiation. Radiat. Res., 172, 114-119.

41. Zheng, Y. and Sanche, L.o. (2013) Low Energy Electrons in Nanoscale Radiation Physics: Relationship to Radiosensitization and Chemoradiation Therapy. Reviews in Nanoscience and Nanotechnology, 2, 1-28.

42. Zu, Y., Huang, S., Liao, W.-C., Lu, Y. and Wang, S. (2014) Gold Nanoparticles Enhanced Electroporation for Mammalian Cell Transfection. Journal of Biomedical Nanotechnology, 10, 982-992.

43. Alkilany, A.M. and Murphy, C.J. (2010) Toxicity and cellular uptake of gold nanoparticles: what we have learned so far? Journal of nanoparticle research : an interdisciplinary forum for nanoscale science and technology, 12, 2313-2333.

44. Kneipp, J., Kneipp, H., McLaughlin, M., Brown, D. and Kneipp, K. (2006) In Vivo Molecular Probing of Cellular Compartments with Gold Nanoparticles and Nanoaggregates. Nano Lett, 6, 2225-2231.

45. Melancon, M.P., Lu, W., Yang, Z., Zhang, R., Cheng, Z., Elliot, A.M., Stafford, J., Olson, T., Zhang, J.Z. and Li, C. (2008) In vitro and in vivo targeting of hollow gold nanoshells directed at epidermal growth factor receptor for photothermal ablation therapy. Molecular cancer therapeutics, 7, 1730-1739.

46. Visaria, R.K., Griffin, R.J., Williams, B.W., Ebbini, E.S., Paciotti, G.F., Song, C.W. and Bischof, J.C. (2006) Enhancement of tumor thermal therapy using gold nanoparticle- 
assisted tumor necrosis factor-alpha delivery. Molecular cancer therapeutics, 5, 10141020.

47. Betancourt, T., Brown, B. and Brannon-Peppas, L. (2007) Doxorubicin-loaded PLGA nanoparticles by nanoprecipitation: preparation, characterization and in vitro evaluation. Nanomedicine (London, England), 2, 219-232.

48. Lee, H., Park, S., Kim, J.B., Kim, J. and Kim, H. (2013) Entrapped doxorubicin nanoparticles for the treatment of metastatic anoikis-resistant cancer cells. Cancer letters, 332, $110-119$.

49. Benbow, U., Schoenermark Mp Fau - Orndorff, K.A., Orndorff Ka Fau - Givan, A.L., Givan Al Fau - Brinckerhoff, C.E. and Brinckerhoff, C.E. (1999) Human breast cancer cells activate procollagenase-1 and invade type I collagen: invasion is inhibited by alltrans retinoic acid.

50. Pille, J.Y., Denoyelle, C., Varet, J., Bertrand, J.R., Soria, J., Opolon, P., Lu, H., Pritchard, L.L., Vannier, J.P., Malvy, C. et al. (2005) Anti-RhoA and Anti-RhoC siRNAs Inhibit the Proliferation and Invasiveness of MDA-MB-231 Breast Cancer Cells in Vitro and in Vivo. Mol Ther, 11, 267-274.

51. Bursch, W., Ellinger A Fau - Kienzl, H., Kienzl H Fau - Torok, L., Torok L Fau Pandey, S., Pandey S Fau - Sikorska, M., Sikorska M Fau - Walker, R., Walker R Fau Hermann, R.S. and Hermann, R.S. (1996) Active cell death induced by the anti-estrogens tamoxifen and ICI 164384 in human mammary carcinoma cells (MCF-7) in culture: the role of autophagy. 
52. Hsieh, C.Y., Santell Rc Fau - Haslam, S.Z., Haslam Sz Fau - Helferich, W.G. and Helferich, W.G. (1998) Estrogenic effects of genistein on the growth of estrogen receptor-positive human breast cancer (MCF-7) cells in vitro and in vivo.

53. Wang, T.T. and Phang, J.M. (1995) Effects of estrogen on apoptotic pathways in human breast cancer cell line MCF-7.

54. Jain, R.K. (2005) Normalization of tumor vasculature: an emerging concept in antiangiogenic therapy. Science, 307, 58-62.

55. Jain, R.K. (1999) Transport of molecules, particles, and cells in solid tumors. Annual Review of Biomedical Engineering, 1, 241-263.

56. Grantab, R., Sivananthan, S. and Tannock, I.F. (2006) The penetration of anticancer drugs through tumor tissue as a function of cellular adhesion and packing density of tumor cells. Cancer Res., 66, 1033-1039.

57. Perrault, S.D., Walkey, C., Jennings, T., Fischer, H.C. and Chan, W.C.W. (2009) Mediating Tumor Targeting Efficiency of Nanoparticles Through Design. Nano Lett., 9, 1909-1915.

58. Tennyson Gs Fau - Lane, B.P. and Lane, B.P. (1981) In vivo and in vitro growth of a rat tracheal squamous cell carcinoma.

59. Minchinton, A.I. and Tannock, I.F. (2006) Drug penetration in solid tumours. Nat Rev Cancer, 6, 583-592.

60. Thomlinson Rh Fau - Thomlinson, R.H. and Gray Lh Fau - Gray, L.H. (1955) The Histological Structure of Some Human Lung Cancers and the Possible Implications for Radiotherapy. 
61. Liotta, L.A. (1986) Tumor invasion and metastases--role of the extracellular matrix: Rhoads Memorial Award lecture.

62. Netti, P.A., Berk Da Fau - Swartz, M.A., Swartz Ma Fau - Grodzinsky, A.J., Grodzinsky Aj Fau - Jain, R.K. and Jain, R.K. (2000) Role of extracellular matrix assembly in interstitial transport in solid tumors.

63. Chen, W., Cormode, D.P., Vengrenyuk, Y., Herranz, B., Feig, J.E., Klink, A., Mulder, W.J., Fisher, E.A. and Fayad, Z.A. (2013) Collagen-specific peptide conjugated HDL nanoparticles as MRI contrast agent to evaluate compositional changes in atherosclerotic plaque regression. JACC.Cardiovascular imaging, 6, 373-384.

64. Goodman, T.T., Olive, P.L. and Pun, S.H. (2007) Increased nanoparticle penetration in collagenase-treated multicellular spheroids. International Journal of Nanomedicine, 2 , 265-274.

65. Stylianopoulos, T., Poh, M.Z., Insin, N., Bawendi, M.G., Fukumura, D., Munn, L.L. and Jain, R.K. (2010) Diffusion of particles in the extracellular matrix: the effect of repulsive electrostatic interactions. Biophysical journal, 99, 1342-1349.

66. Wang, S.H., Lee, C.W., Chiou, A. and Wei, P.K. (2010) Size-dependent endocytosis of gold nanoparticles studied by three-dimensional mapping of plasmonic scattering images. Journal of nanobiotechnology, 8, 33-3155-3158-3133.

67. Ramanujan, S., Pluen, A., McKee, T.D., Brown, E.B., Boucher, Y. and Jain, R.K. (2002) Diffusion and convection in collagen gels: implications for transport in the tumor interstitium. Biophysical journal, 83, 1650-1660. 
68. Yang, C., Neshatian, M., Hegarty, N. and Chithrani, B.D. (2013) Gold-based Nanostructures for Improved Cancer Therapeutics. Nanotechnology 2013: Technical Proceedings of the 2013 NSTI Nanotechnology Conference and Expo, 3, 335-338.

69. Huang, H.-C., Ramos, J., Grandhi, T.S.P., Potta, T. and Rege, K. (2010) Gold Nanoparticles In Cancer Imaging and Therapeutics. Nano LIFE, 01, 289-307.

70. Au, L., Zheng, D., Zhou, F., Li, Z.Y., Li, X. and Xia, Y. (2008) A Quantitative Study on the Photothermal Effect of Immuno Gold Nanocages Targeted to Breast Cancer Cells. ACS Nano, 2, 1645-1652.

71. Chen, J., Glaus, C., Laforest, R., Zhang, Q., Yang, M., Gidding, M., Welch, M.J. and Xia, Y. (2010) Gold Nanocages as photothermal Transducers for Cancer Treatment. Small, 6, 811-817.

72. Chen, J., Wang, D., Xi, J., Au, L., Siekkinen, A., Warsen, A., Li, Z.Y., Zhang, H., Xia, Y. and Li, X. (2007) Immuno Gold Nanocages with Tailored Optical Properties for Targeted Photothermal Destruction of Cancer Cells. Nano Lett., 7, 1318.

73. Choi, W.I., Kim, J.-Y., Kang, C., Byeon, C.C., Kim, Y.H. and Tae, G. (2011) Tumor regression in vivo by photothermal therapy based on gold-nanorod-loaded, functional nanocarriers. ACS nano, 5, 1995-2003.

74. Green, H.N., Martyshkin, D.V., Rodenburg, C.M., Rosenthal, E.L. and Mirov, S.B. (2011) Gold nanorod bioconjugates for active tumor targeting and photothermal therapy. Journal of Nanotechnology, 2011.

75. Huang, X., Jain, P.K., El-Sayed, I.H. and El-Sayed, M.A. (2008) Plasmonic photothermal therapy (PPTT) using gold nanoparticles. Lasers in medical science, 23, 217-228. 
76. Amelink, A., van der Ploeg van den Heuvel, A., de Wolf, W.J., Robinson, D.J. and Sterenborg, H.J. (2005) Monitoring PDT by means of superficial reflectance spectroscopy. Journal of photochemistry and photobiology.B, Biology, 79, 243-251.

77. Bechet, D., Couleaud, P., Frochot, C., Viriot, M.L., Guillemin, F. and Barberi-Heyob, M. (2008) Nanoparticles as vehicles for delivery of photodynamic therapy agents. Trends in biotechnology, 26, 612-621.

78. Chatterjee, D.K., Fong, L.S. and Zhang, Y. (2008) Nanoparticles in photodynamic therapy: an emerging paradigm. Advanced Drug Delivery Reviews, 60, 1627-1637.

79. Chen, W. and Zhang, J. (2006) Using nanoparticles to enable simultaneous radiation and photodynamic therapies for cancer treatment. J. Nanosci. Nanotechnol., 6, 1159-1166.

80. Cheng, Y., C. Samia, A., Meyers, J.D., Panagopoulos, I., Fei, B. and Burda, C. (2008) Highly efficient drug delivery with gold nanoparticle vectors for in vivo photodynamic therapy of cancer. Journal of the American Chemical Society, 130, 10643-10647.

81. Bao, G., Mitragotri, S. and Tong, S. (2013) Multifunctional nanoparticles for drug delivery and molecular imaging. Annual Review of Biomedical Engineering, 15, 253-282.

82. Cheng, J., Gu, Y.J., Cheng, S.H. and Wong, W.T. (2013) Surface functionalized gold nanoparticles for drug delivery. Journal of biomedical nanotechnology, 9, 1362-1369.

83. Cheng, Y., Samia, A.C., Meyers, J.D., Panagopoulos, I., Fei, B. and Burda, C. (2008) Highly Efficient Drug Delivery with Gold Nanoparticle Vectors for in Vivo Photodynamic Therapy of Cancer. J. Am. Chem. Soc., 130, 10643-10647.

84. Duncan, B., Kim, C. and Rotello, V.M. (2010) Gold nanoparticle platforms as drug and biomacromolecule delivery systems. Journal of Controlled Release, 148, 122-127. 
85. Han, G., Ghosh, P., De, M. and Rotello, V.M. (2007) Drug and gene delivery using gold nanoparticles. NanoBioTechnology, 3, 40-45.

86. Brun, E., Sanche, L.o. and Sicard-Roselli, C.c. (2009) Parameters governing gold nanoparticle X-ray radiosensitization of DNA in solution. Colloids and Surfaces B: Biointerfaces, 72, 128-134.

87. Chithrani, D.B., Jelveh, S., Jalali, F., van Prooijen, M., Allen, C., Bristow, R.G., Hill, R.P. and Jaffray, D.A. (2010) Gold nanoparticles as radiation sensitizers in cancer therapy. Radiation research, 173, 719-728.

88. Hainfeld, J.F., Slatkin, D.N. and Smilowitz, H.M. (2004) The use of gold nanoparticles to enhance radiotherapy in mice. Phys. Med. Biol., 49, N309-N315.

89. Kim, D.Y., Yu, T., Cho, E.C., Ma, Y., Park, O.O. and Xia, Y. (2011) Berichtigung: Synthesis of Gold Nano-hexapods with Controllable Arm Lengths and Their Tunable Optical Properties. Angewandte Chemie, 123, 8120-8120.

90. Chen, J., Saeki, F., Wiley, B.J., Cang, H., Cobb, M.J., Li, Z.Y., Au, L., Zhang, H., Kimmey, M.B., Li, X. et al. (2005) Gold Nanocages: Bioconjugation and Their Potential Use as Optical Imaging Contrast Agents. Nano Lett., 5, 473-477.

91. Li, Y., Schluesener, H. and Xu, S. (2010) Gold nanoparticle-based biosensors. Gold Bulletin, 43, 29-41.

92. Lin, A.W.H., Lewinski, N.A., West, J.L., Halas, N.J. and Drezek, R.A. (2005) Optically tunable nanoparticle contrast agents for early cancer detection: model-based analysis of gold nanoshells. Journal of Biomedical Optics, $\mathbf{1 0}$. 
93. Wang, Y., Black, K.C., Luehmann, H., Li, W., Zhang, Y., Cai, X., Wan, D., Liu, S.Y., Li, M., Kim, P. et al. (2013) Comparison study of gold nanohexapods, nanorods, and nanocages for photothermal cancer treatment. ACS nano, 7, 2068-2077.

94. Zhu, J., Gong, T., Kopwitthaya, A., Hu, R., Law, W.-C., Roy, I., Huang, H. and Yong, K.-T. (2013) Synthesis of PEGylated gold nanorods (Au NRs) as absorption nanoprobes for near-infrared optical imaging. RSC Advances, 3, 12280.

95. Anshup, Venkataraman, J.S., Subramaniam, C., Kumar, R.R., Priya, S., Kumar, T.R.S., Omkumar, R.V., John, A. and Pradeep, T. (2005) Growth of gold nanoparticles in human cells. Langmuir, 21, 11562-11567.

96. Arnida, Malugin, A. and Ghandehari, H. (2010) Cellular uptake and toxicity of gold nanoparticles in prostate cancer cells: a comparative study of rods and spheres. Journal of Applied Toxicology, 30, 212-217.

97. Yang, C., Uertz J Fau - Yohan, D., Yohan D Fau - Chithrani, B.D. and Chithrani, B.D. (2014) Peptide modified gold nanoparticles for improved cellular uptake, nuclear transport, and intracellular retention. Nanoscale.

98. Yohan, D. and Chithrani, B.D. (2014) Applications of Nanoparticles in Nanomedicine. Journal of Biomedical Nanotechnology, 10, 2371-2392.

99. Turkevich, J., Hillier, J. and Stevenson, P.C. (1951) A study of the nucleation and growth processes in the synthesis of colloidal gold. Discuss Faraday Soc, 11, 55-75.

100. Frens, G. (1973) Controlled nucleation for the particle size in monodisperse gold suspensions. Nature, 241, 20-22. 
101. Chithrani, B.D. and Chan, W.C. (2007) Elucidating the mechanism of cellular uptake and removal of protein-coated gold nanoparticles of different sizes and shapes. Nano letters, 7, 1542-1550.

102. Chithrani, B.D., Ghazani, A.A. and Chan, W.C. (2006) Determining the size and shape dependence of gold nanoparticle uptake into mammalian cells. Nano letters, 6, 662-668.

103. Khlebtsov, N.G. (2008) Determination of Size and Concentration of Gold Nanoparticles from Extinction Spectra. Anal chem, 80, 6620-6625.

104. Gao, H., Shi W Fau - Freund, L.B. and Freund, L.B. (2005) Mechanics of receptormediated endocytosis. Proc Natl Acad Sci U S A.

105. Zhang, S., Li, J., Lykotrafitis, G., Bao, G. and Suresh, S. (2009) Size-Dependent Endocytosis of Nanoparticles. Advanced materials, 21, 419-424.

106. Jain, R.K. (2001) Delivery of molecular and cellular medicine to solid tumors. Adv Drug Deliv Rev. .

107. Kuppen, P.J., van der Eb Mm Fau - Jonges, L.E., Jonges Le Fau - Hagenaars, M., Hagenaars M Fau - Hokland, M.E., Hokland Me Fau - Nannmark, U., Nannmark U Fau Goldfarb, R.H., Goldfarb Rh Fau - Basse, P.H., Basse Ph Fau - Fleuren, G.J., Fleuren Gj Fau - Hoeben, R.C., Hoeben Rc Fau - van de Velde, C.J. et al. (2001) Tumor structure and extracellular matrix as a possible barrier for therapeutic approaches using immune cells or adenoviruses in colorectal cancer. Histochem Cell Biol.

108. Kaul, G. and Amiji, M. (2005) Tumor-targeted gene delivery using poly(ethylene glycol)-modified gelatin nanoparticles: in vitro and in vivo studies. Pharm Res.

109. Flessner, M.F., Choi J Fau - Credit, K., Credit K Fau - Deverkadra, R., Deverkadra R Fau - Henderson, K. and Henderson, K. (2005) Resistance of tumor interstitial pressure to the 
penetration of intraperitoneally delivered antibodies into metastatic ovarian tumors. Clin Cancer Res.

110. Minchinton, A.I., Wendt Kr Fau - Clow, K.A., Clow Ka Fau - Fryer, K.H. and Fryer, K.H. (1997) Multilayers of cells growing on a permeable support. An in vitro tumour model. Acta Oncol., 1, 13-16.

111. Cowan, D.S., Hicks, K.O. and Wilson, W.R. (1996) Multicellular membranes as an in vitro model for extravascular diffusion in tumours. The British Journal of Cancer. Supplement, 27, S28-S31.

112. Tannock, I.F., Lee, C.M., Tunggal, J.K., Cowan, D.S. and Egorin, M.J. (2002) Limited penetration of anticancer drugs through tumor tissue: a potential cause of resistance of solid tumors to chemotherapy. Clin Cancer Res, 8, 878Ã đâ, ᄀâ€œ884.

113. Hicks, K.O., Fleming Y Fau - Siim, B.G., Siim Bg Fau - Koch, C.J., Koch Cj Fau Wilson, W.R. and Wilson, W.R. (1998) Extravascular diffusion of tirapazamine: effect of metabolic consumption assessed using the multicellular layer model. Int J Radiat Oncol Biol Phys., 42, 641-649.

114. Wilson, W.R. and Hicks, K.O. (1999) Measurement of extravascular drug diffusion in

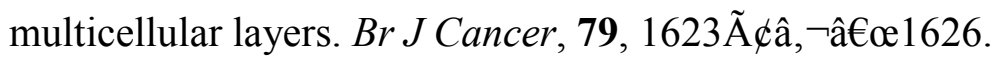

115. Phillips, R.M., Loadman Pm Fau - Cronin, B.P. and Cronin, B.P. (1998) Evaluation of a novel in vitro assay for assessing drug penetration into avascular regions of tumours. $\mathrm{Br} J$ Cancer., 12, 2112-2119.

116. Neshatian, M., Chung, S., Yohan, D., Yang, C. and Chithrani, D.B. (2015) Uptake of Gold Nanoparticles in Breathless (Hypoxic) Cancer Cells. Journal of Biomedical Nanotechnology, 11, 1162-1172. 


\title{
Elucidating the Uptake and Distribution of Nanoparticles in Solid Tumors via a Multilayered Cell Culture Model
}

\author{
Darren Yohan \\ Master of Science \\ Biomedical Physics, 2015 \\ Ryerson University
}

\subsection{0 - Abstract}

Multicellular Layers (MCLs) have previously been used to determine the pharmokinetics of a variety of different cancer drugs including paclitaxel, doxorubicin, methotrexate, and 5fluorouracil across a number of cell lines. It is not known how nanoparticles (NPs) navigate through the tumor microenvironment once they leave the tumor blood vessel. In this study, we used the MCL model to study the uptake and penetration dynamics of NPs. GNPs were used as a model NP system to map the NP distribution within tissue-like structures. Our study showed that NP uptake and transport is dependent on the tumor cell type. MDA-MB231 tissue showed deeper penetration of GNPs as compared to MCF-7. Intracellular and extracellular distribution of NPs was mapped using CytoViva imaging. The ability of MCLs to mimic tumor tissue characteristics makes them a useful tool in assessing the efficacy of particle distribution in solid tumors.

This research has been published in Volume 7, Issue 2 (pp127-137) of Nano-Micro Letters in April 2015. Reproduced with permission from Springer Group. 


\subsection{1 - Introduction}

Recent progress in the use of nanotechnology for biomedical research has led to the development of materials called "nanoparticles (NPs)" for improved therapeutics and imaging in cancer therapy (1-3). Cancer nanotechnology allows for the development of safer yet more effective diagnostic and therapeutic modalities for cancer therapy (4-6). The ultimate goal of nanoparticle (NP)-based platforms will be the targeted delivery and monitoring of therapeutics to tumors while causing minimum side effects (7-11).Among other NP-systems, gold nanoparticles (GNPs) play a significant role in cancer therapeutics because they: a) can enhance the damage induced by radiation and anticancer drugs, b) produce heat upon exposure to UV and Near Infra Red (NIR) radiation and hence provide the possibility of destruction of cancer cells through thermal ablation, c) enhance the delivery of drugs that are highly water-insoluble or unstable in the biological environment, d) increase the lifetime of drugs and imaging agents through NP-surface modification to avoid drug loss due to rapid clearance and metabolism (12-14). Hence, gold nanostructures are being used as a therapeutic agent in radiation therapy (RT), chemotherapy, photothermal therapy (PTT), and photodynamic therapy (PDT). These new opportunities encourage innovations leading to effective combinational therapy in the fight against cancer(2).However, the success of such innovations relies on GNP distribution and penetration throughout the tumor. To reach cancer cells in optimal quantities, therapeutic agents must be delivered to tumors through an imperfect blood vascular system, cross vessel walls into the interstitium, and penetrate multiple layers of tissue (see Fig. 1A,B) (15). In this study, we used multicellular layers (MCLs) to mimic tumor tissue to study the penetration and uptake of GNPs in a tumor-like microenvironment. 


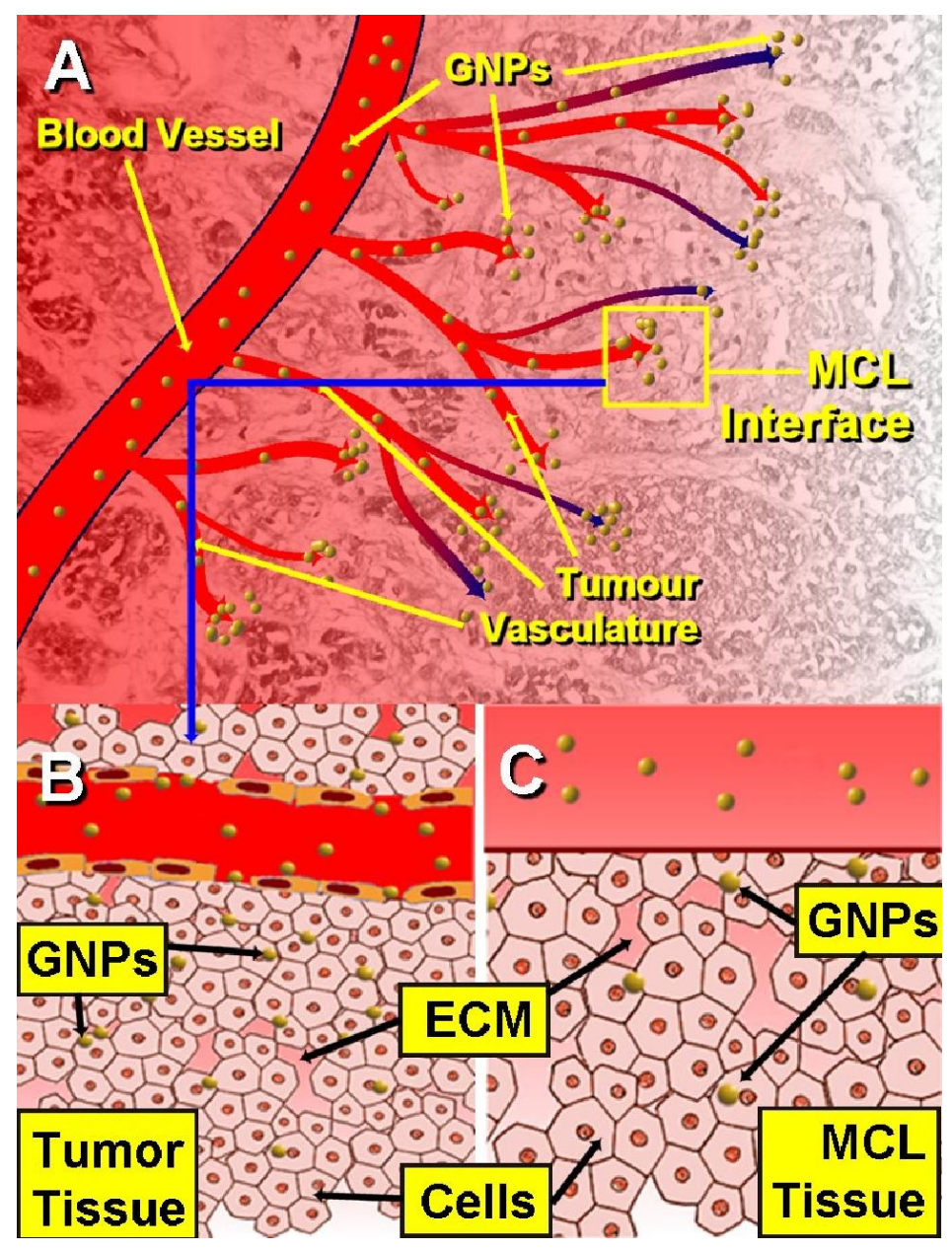

Figure 1: Use of MCL cell model to understand the NP transport through the tumor tissue. A, Transport of GNPs through the blood vessels and enters tumor vasculature. The interface between tumor vasculature and tumor tissue is highlighted with a yellow box. B, GNPs escape the tumor vasculature through leaky endothelial cells (1) and enter tumor cells through ECM. C, Description shown in B is modeled using proposed MCL cell model. MCL act as a tumor tissue being fed by tissue culture media containing GNPs (2).

The MCLs, developed by Wilson and his colleagues, provides a quantitative method that permits direct assessment of drug penetration through solid tissue $(16,17)$. MCLs share several properties with solid tumors derived from the same cell type, including a similar but not identical extracellular matrix (ECM) and tight junctions between epithelial cells (18). In addition, MCLs have been shown to exhibit areas of hypoxia, necrosis, as well as nutrient and proliferation 
gradients and ECM generation(19-21). The development of MCL models has facilitated quantification of drug penetration through solid tissue. Although the direct in vivo assessment, when feasible, has the advantage of duplicating the clinical environment most closely, in vitro techniques offer the advantage of being able to examine the distribution of agents of interest in the absence of complicating factors such as pharmacokinetics and hepatic metabolism, which often differ between mice and humans (21). 

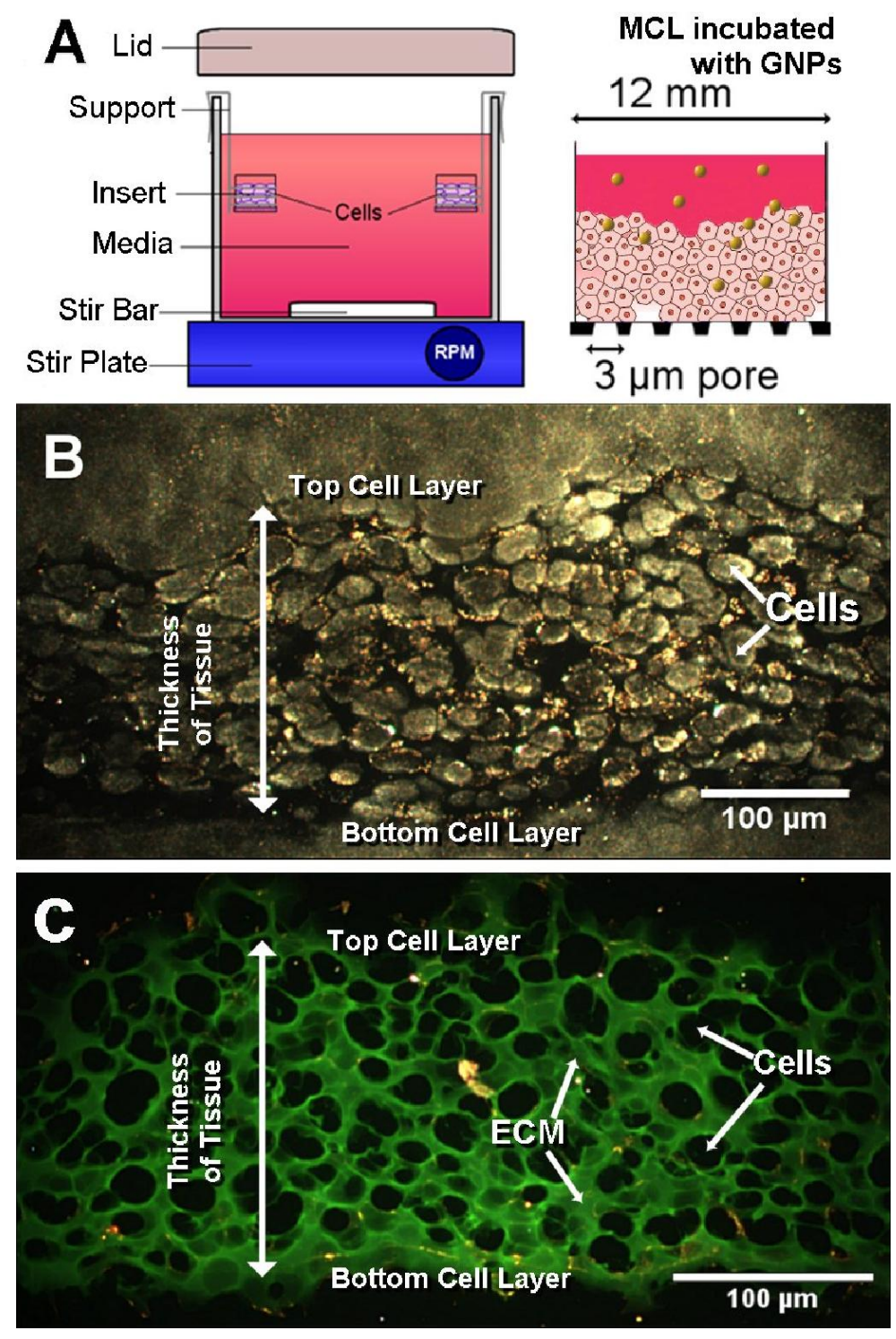

Figure 2: Growth of MCLs. A, Diagrammatic representation of the apparatus used to culture MCLs. Tissue culture inserts are held suspended in stirred media (top left). The set-up was placed in a humidified incubator with $5 \% \mathrm{O}_{2}, 5 \% \mathrm{CO}_{2}, 95 \% \mathrm{~N}_{2}$. After the growth, GNPs were introduced into the media to investigate the NP transport through tissue (top right). B, A crosssection of an unstained MCF-7 tissue. C, A cross-section of a MCF-7 tissue stained with eosin to map the ECM. Areas marked in green belong to ECM while the unstained regions represent cells.

In this study, we examine for the first time the ability of NPs to penetrate and distribute through an MCL, which is designed to mimic the environment of solid tumor tissue (see Fig. 2). The MCL offers a model to study the transport of NPs across the tumor tissue once it leaves the blood 
vessel (Fig. 1C). The success of the NP-based imaging and therapy depends on their delivery to tumor tissue through blood vessels as illustrated in Fig. 1A. It is known that NPs can leak out through the tumor blood vessels and enter the tumor tissue as illustrated in Fig. 1B. In this study, we grew tissue-like MCLs of up to $130-150 \mu \mathrm{m}$ to study the NP transport and uptake in tumor tissue (Fig. 2B). Since the proliferation of tumor cells can outpace the proliferation of cells that form blood vessels, vascular density can be reduced, and the of cells as far as $100 \mu \mathrm{m}$ from blood vessels is possible (22-24). In addition, previous studies have shown that the presence of ECM in solid tumor tissue can affect the transport of molecules into tumor cells (2527). These MCLs would also consist of ECM which is similar but not identical to the ones in solid tumors(18). Hence, our MCL model creates a reasonable tumor microenvironment to study NP transport in tumor tissue. Elucidation of NP uptake and transport in tissue-like structures will bridge the gap between in vitro single-layer cell models and the in vivo tumor models. Better understanding of the interface between nanotechnology and biology would accelerate development of clinical-based applications.

\subsection{2 - Materials and Methods}

\section{Synthesis of GNPS}

The GNPs were synthesized via the reduction of $\mathrm{HAuCl}_{4}$ by sodium citrate, which is more commonly referred to as the Turkevitch Method (28). By varying the amount of sodium citrate, the method can yield nanoparticles of varying sizes. In this study, 20nm particles were chosen since our future goal is to use these NPs for gene delivery. The GNPs were characterized by Transmission Electron Microscopy (H7000; Hitachi Corp., Tokyo, Japan), UV-spectroscopy (Lambda 40; PerkinElmer, Waltham, MA) and by Dynamic Light Scattering using 90 Plus 
Particle Sizer Analyzer (Brookhaven Instruments Corp., New York, NY) to determine the size of the particles.
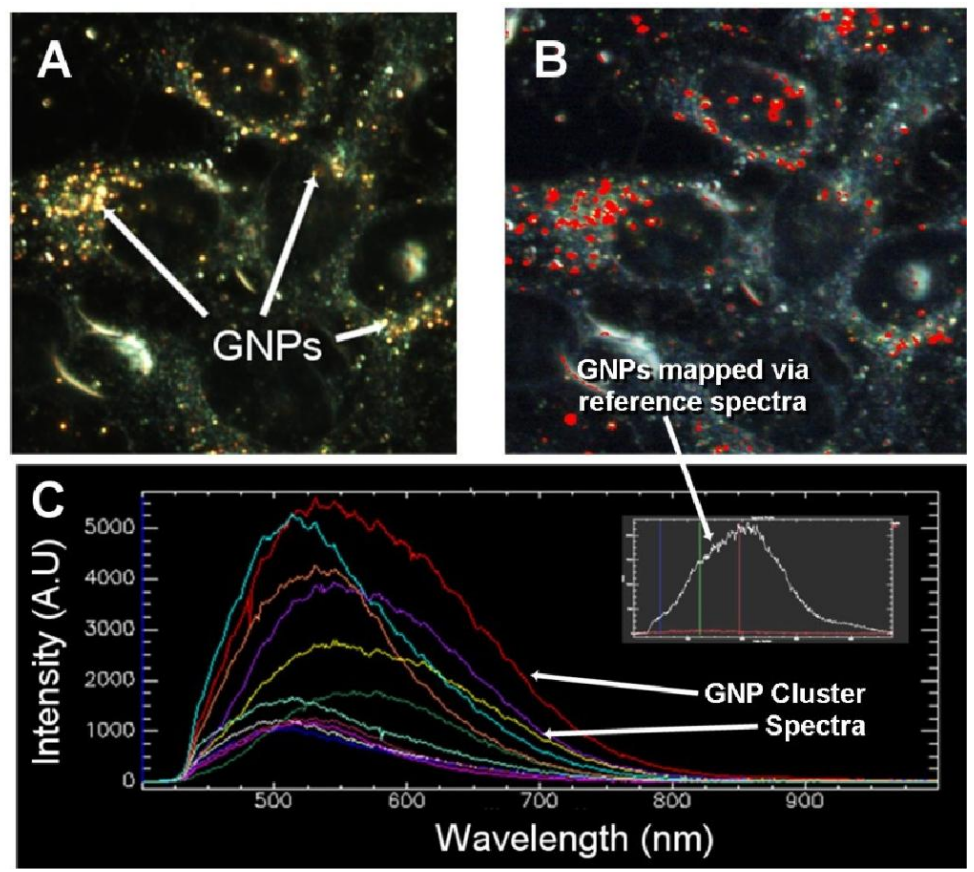

Figure 3: Visualization and mapping of GNPs in cells using CytoViva hyperspectral Imaging (HSI) optical microscopy. A, The unmapped dark field HSI image with GNPs visible as bright spots. B, The result of a spectral angle mapping on the HSI image. GNPs have been labeled red as a result of matching spectra from individual pixels. C, GNP spectra from few NP clusters localized within cells and the reference spectra (inset) used to create the spectral angle map in B.

\section{Growth of MCLs}

The growth of the MCLs began with the growth of monolayer cells in a $5 \% \mathrm{CO}_{2}$ environment at $37^{\circ} \mathrm{C}$. After reaching confluence, these cells were trypsinized, centrifuged, suspended in media, and counted. Approximately 150 000-200 000 cells were seeded onto a microporous membrane insert (Millicell, Bedford, MA). After allowing the cells to attach for two to four hours, the inserts were washed with PBS and then suspended in stirred media to grow. With pore sizes of 3 
$\mu \mathrm{m}$, the inserts allowed for the passage of stirred media through the base of the insert as seen in

Fig. 2 A.
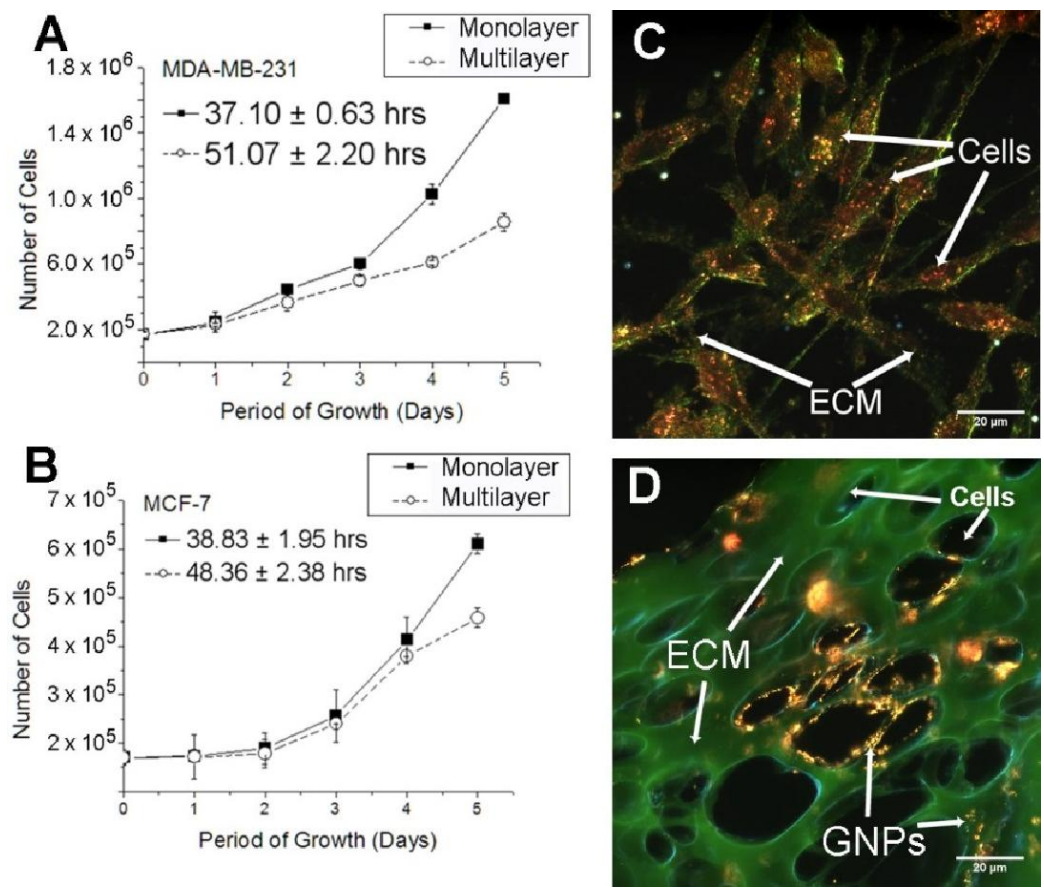

Figure 4: Characterization of monolayer and multilayer cell structures. A-B, Comparison of growth curves for the MDA-MB-231 and MCF-7 cell lines at monolayer and multilayer level, respectively. C-D,A monolayer and multilayer cross-section of MDA-MB-231 cells stained with eosin to highlight the ECM, respectively. Cell population doubling times for MCF-7 and MDA-

MB-231 monolayer cell cultures were 38.83 and $37.10 \mathrm{hrs}$, respectively. Cell population doubling times for MCF-7 and MDA-MB-231 multilayer cell cultures were 48.36 and $51.07 \mathrm{hrs,}$ respectively. Error bars represent the standard deviation and $n=3$.

Two breast cancer cell lines were used in this study: MCF-7 and MDA-MB-231. Cells were grown on the MCL insert in Dulbecco's Modified Eagle's Medium with 10\% Fetal Bovine Serum (Sigma-Aldrich, Oakville, ON). Varying the growth time can control the thickness of the MCL. Figure 2B is an image of an unstained tissue cross-section of MCF-7 cells. The ECM within the tissue was stained with eosin for visualization (Fig. 2C). The thickness of the tissue was controlled by the growth period. NP incubation of the MCLs was done by hanging the MCLs in multiwall plates and filling the top of the inserts with the GNP and media mixture. A supply of 
fresh media was placed below the MCL to allow for GNPs that had penetrated the entire MCL structure.

Quantification of GNP uptake
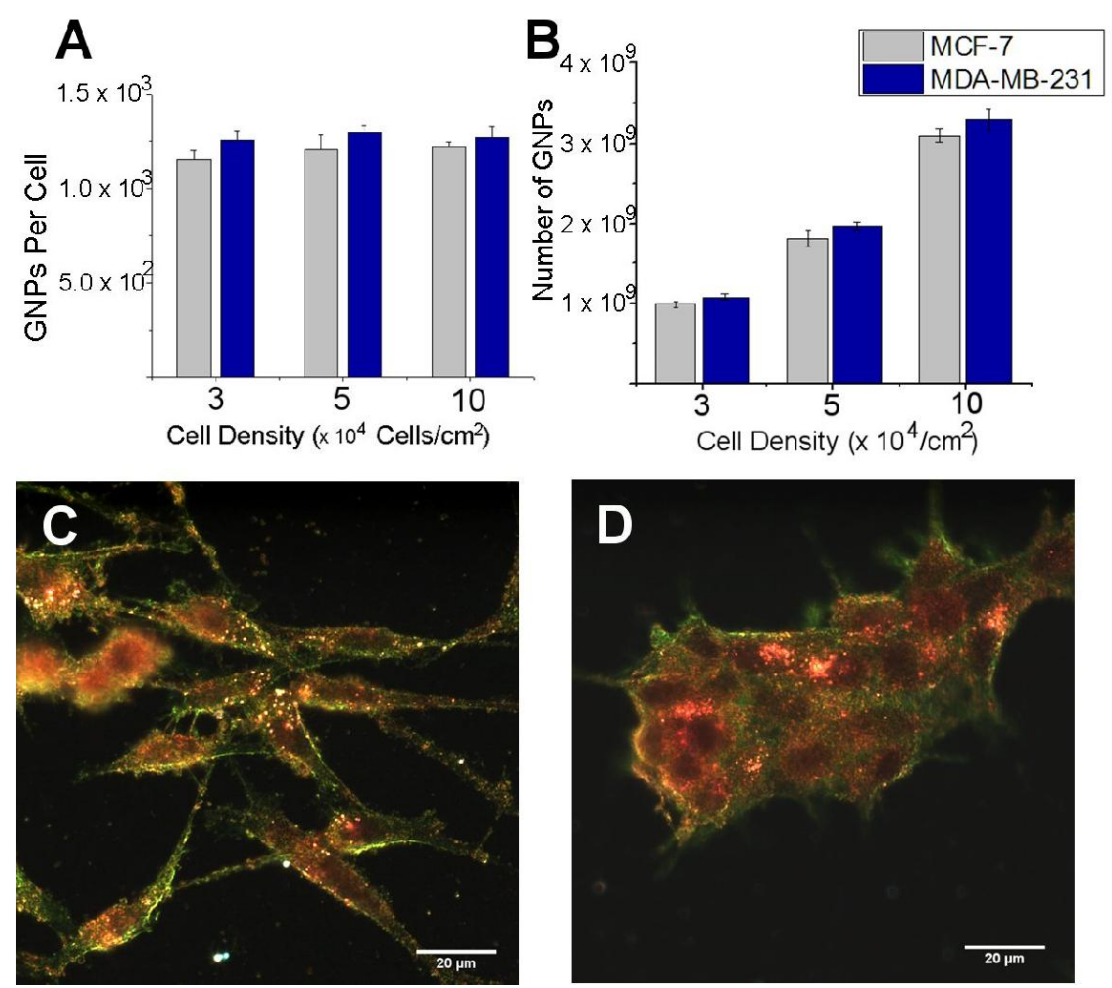

Figure 5: GNP uptake in monolayer cell models. A, NP uptake per cell as a function of cell density. B, Total uptake of NPs as a function of cell density. C and D show samples of H\&E stained monolayer MDA-MB-231 and MCF-7 cells with GNPs present mostly in the cells. Error bars represent the standard deviation and $n=3$.

During incubation, the MCL structures were hung in multi-well plates with a $15 \mathrm{nM} \mathrm{GNP/media}$ mixture on the top and a supply of fresh media on the bottom. Both the 'top' and 'bottom' volumes were collected and measured for gold content via ICP-AES (Inductively Coupled Plasma -Atomic Emission Spectroscopy) (Optima 7300 DV; PerkinElmer, Waltham, MA). By using a known concentration of GNPs, this method allows for the measurement of uptake and penetration through tissue, which results from taking the difference between the 'top' and 
'bottom' samples. Monolayer cultures were also grown and harvested at different time points constituting 3 cell densities. These cultures were incubated with GNPs for 24 hours and were used for cell counting and monolayer gold uptake measurement via ICP-AES.

Qualitative Analysis
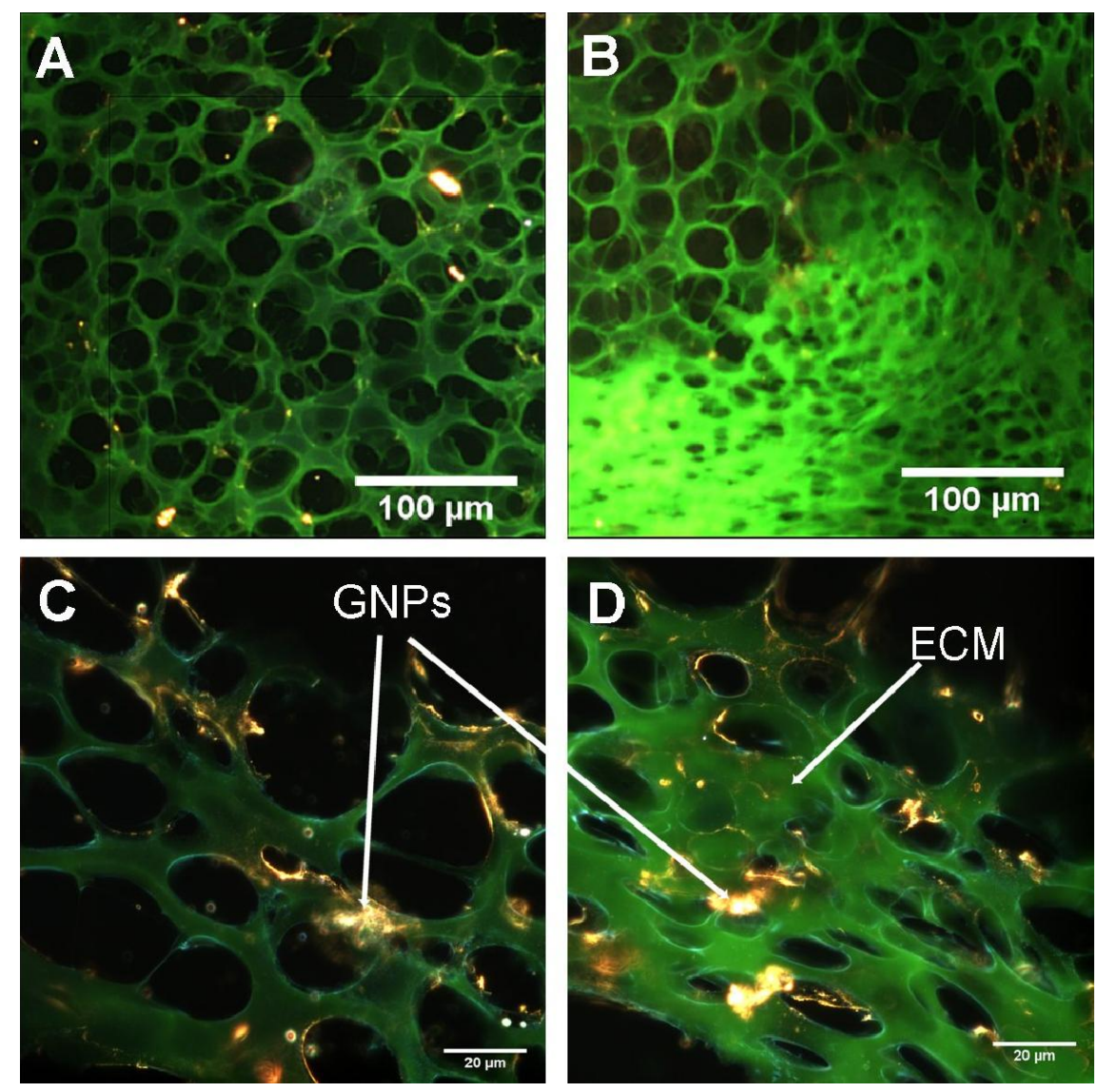

Figure 6: Differences in extracellular matrix (ECM) in MDA-MB-231 and MCF-7 tissue structures. A and C, MCL tissue of MCF-7 cells at 10x and 60x magnification, respectively. B and D, MCL tissue of MDA-MB-231 cells at 10x and 60x, respectively. Differences in the ECM structure can be seen at both magnifications. MCF-7 tissue had a much more organized ECM structure while MDA-MB-231 tissue has a disorganized ECM structure which allowed easy penetration of molecules into deeper tissues. 
To qualitatively measure the distribution of the GNPs as well as to provide a measure of MCL growth characteristics, MCL inserts were frozen in OCT compound for sectioning. The frozen MCLs were then sectioned (Cryostat CM1900; Leica, Wetzlar, Germany) into 15-20 $\mu \mathrm{m}$ thick sections and placed onto slides for imaging. Tissue sections were stained with eosin to show the presence of ECM (Autostainer XL; Leica, Wetzlar, Germany). Stained tissue sections were imaged using the CytoViva Hyper Spectral Imaging (HSI) dark-field microscope.

CytoViva imaging of NP distribution in MCLs

The CytoViva technology used in this study was specifically designed for optical observation and spectral confirmation of NPs as they interact with cells and tissues. The illumination of the microscope system utilizes oblique angle illumination to create high SNR dark-field images. Figure 3A is a dark-field image of a group of cells with internalized GNPs. The GNPs appear bright, owing to their high scattering cross-section. A Hyperspectral Imaging System was used in conjunction with the dark-field microscope to obtain reflectance spectra from each pixel in the dark-field image. Spectral Angle Mapping can be performed to conduct a pixel-by-pixel matching of any spectra obtained by the system. This procedure was used to create a map of GNPs based on their reflectance spectra within the sample. The hyperspectral image shows which pixel matched the known GNP spectrum within a given spectral angle threshold set at 0.15 radians for this study. Figure 3B shows the hyperspectral image with an overlaid spectral angle map where the red dots represent matching GNP spectra. Figure 3C shows reflectance spectra from one of the red dots and the reference spectrum (white color) to which pixels were matched. The background reflectance spectra from the cytoplasm and ECM are shown. It can be clearly seen that the GNP clusters have a very distinct reflectance spectra compared to the background. 


\subsection{3 - Results and discussion}

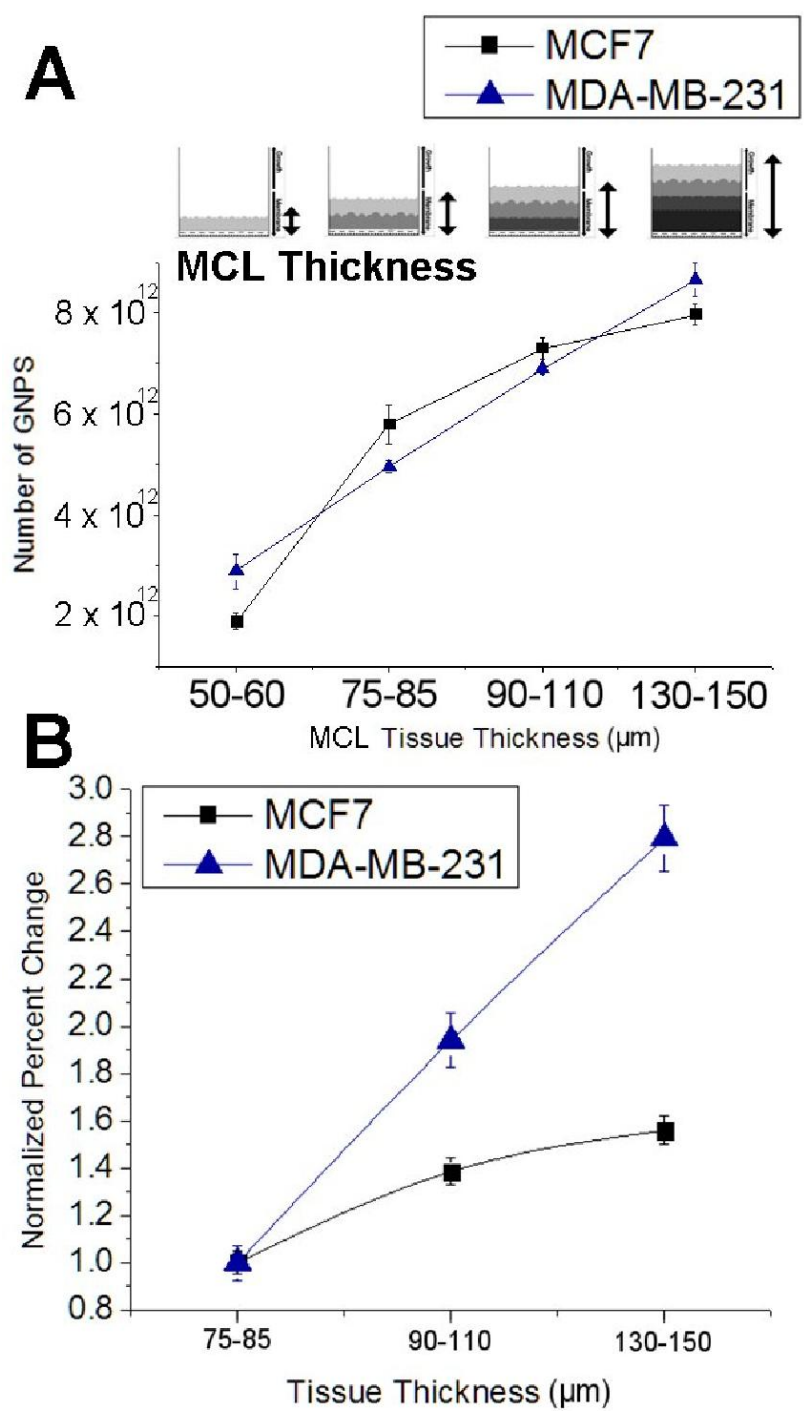

Figure 7: GNP uptake in multilayer cell models. A, Accumulation of GNPs in tissue as a function of its thickness. NPs were able to penetrate deep into tissue in MDA-MB-231 tissue due to the break down in ECM matrix. In MCF-7 tissue, most NPs were localized at the top layers and properly organized ECM acted as a barrier for their transport deep into the tissue. B, The normalized percent increase in GNP uptake as a function of tissue thickness. Error bars represent the standard deviation and $n=3$.

In this study, we were able to demonstrate for the first time the differences in GNP uptake between monolayer and tissue-like MCL cell models. GNPs are being used as a radiation dose enhancer, anticancer drug carrier, and as an imaging contrast agent in cancer research, as 
discussed in the introduction. However, the success of NP-based imaging and therapy depends on the efficiency of delivery of NPs tumor tissue as illustrated in Fig. 1A. In this study, we investigated the NP transport across tumor tissues by using MCL cell models for the first time. It was successfully used to understand anticancer drug diffusion in tissues. The results were consistent with the drug diffusion in solid tumor in animal models.

It is known that NPs can leak out through the disorganized endothelial cells in tumor blood vessels and enter the tumor tissue (Fig. 1B). In particular, this MCL model was used to study the transport of NPs across the tumor tissue once they leave the blood vessel (Fig. 1C). The device used for growing MCLs is shown in Fig. 2A. A tissue cross-section of an approximately $150 \mu \mathrm{m}$ thick MCF-7 cell is shown in Fig. 2B,C. An unstained tissue cross-section is shown in Fig. 2B while a tissue cross-section stained with eosin to highlight the ECM is shown in Fig. 2C. We used the CytoViva HSI technique to image the tissue and NPs. Unlike other optical imaging techniques, HSI allows us to map the GNPs via reflectance spectroscopy. This imaging technology does not require optically labeling NPs for their visualization. This is the first time that such imaging technology was used to visualize GNP distribution in tissue-like structures. Figure 3A shows the unmapped dark-field HSI image with GNPs visible as bright yellow spots, while Fig. 3B shows the result of spectral angle mapping on the HSI image. GNPs have been labeled red as a result of matching spectra (shown as an inset figure in Fig. 3C) from individual pixels. Figure 3C shows a few spectra from GNP clusters displayed in Fig. 3A. This imaging technique was used to map the NP distribution through the tissue. Our first goal was to investigate the difference between monolayer and MCL cell models in terms of growth before investigating the NP uptake and transport. 
We monitored the growth of monolayer and multilayer cell samples over a period of time to understand the difference between these two cell models. As shown in Fig. 4, MCLs differed from the monolayer cultures in terms of growth and ECM generation. Both cell lines showed an increase in population doubling time in the MCLs (Fig. 4A, B). For example, the population doubling time was increased from 37 (at monolayer level) to $51 \mathrm{hrs}$ (at multilayer level) for MDA-MB-231 while it was from 39 (at monolayer level) to $48 \mathrm{hrs}$ (at multilayer level) for MCF7. Increase in population doubling time has previously been demonstrated for cell lines growing as solid tumors in vivo (29-31). Earlier work has shown that MCLs develop oxygen, proliferation, and nutrient gradients that lead to deficiencies in their availability across the MCL sample $(19,20,32)$. However, in the case of monolayer cell cultures, the uniform availability of oxygen and nutrients is likely a major contributor to the lower doubling time $(29,33,34)$. Figures 4C,D show that there is significant increase in the presence of ECM (areas marked in green) in MCLs in contrast to monolayer cell cultures. The data is shown for the MDA-MB-231 cell line. Similar results were obtained for the MCF-7 cell line as well. There were major increases in the presence of ECM in the MCLs for both cell lines. ECM in the MCLs also appears thicker and more structured as compared to the monolayer level. In addition, GNPs (yellowish brown small dot-like structures) were mostly localized within the cells in monolayer cell cultures (Fig. 4C). However, GNPs were localized in both the ECM and cells in the MCL cell cultures (Fig. 4D). Hence, one of the goals of this study was to understand how much effect this ECM has over NP transport at tissue level.

We have also quantified the NP uptake and transport in monolayer and MCL cell models. At the monolayer level, NP uptake per cell was mostly independent of the cell density (see Fig.5). This is likely due to the fact that GNPs introduced into monolayer cultures have immediate access to 
all cells thus enabling the efficient uptake of GNPs per cell. For example, NPs did not need to transport through a dense ECM. Optical images showed that most of the NPs were localized within the cells and the presence of ECM was minimal (Fig. 5 B, C). In the next section, we will discuss the differences in ECM generated for MCF-7 and MDA-MB-231 cell lines before discussing the NP transport through these tissue structures.

The difference in ECM between the two MCL cell models (MCF-7 and MDA-MB-231) is made apparent in Fig. 6 where both were stained with eosin and appear green when viewed with a dark-field condenser. The ECM of MDA-MB-231 appears far less organized than the ECM of MCF-7. The ECM of MCF-7 presents ordered scaffolding with cells separated in distinct layers throughout the structure (Fig. 6A, C) whereas the cell layers are much less compartmentalized in the MDA-MB-231 ECM (Fig. 6B, D). It has been suggested that aggressively invasive tumor cells like MDA-MB-231 secrete matrix-degrading proteinases that serve to break down collagen (35-37). The degradation of the collagen network in the ECM has been shown to significantly diminish the ability of the ECM to control the flow of interstitial traffic $(25,38-40)$. This breakdown of ECM is not as apparent in the non-invasive MCF-7 cell line and ECM will act as a barrier for NP transport. It is clear that ECM of different tumor cell lines can vary and these models will play a bigger role in optimizing NP-based therapeutic and imaging systems before moving into in vivo studies. In the next section, we discuss how the differences in ECM can affect the NP transport through these tissue-like MCL models.

Our investigation of NP transport in tissue-likeMCL models showed that the NP penetration in tissue was dependent on the tumor cell line and it could be due to the differences in their ECM structure as discussed in the previous section (Fig. 7). At monolayer cell cultures, there was a linear increase in NP uptake as a function of cell density (Fig. 5). However, we noticed a 
deviation from this linear increase in NP uptake especially in MCF-7 multilayer structures (Fig.7). This reduction in uptake as a function of tissue depth was also apparent for a number of anti-cancer drugs, and is likely a major contributor to resistance to drugs in tumors $(18,21,41$, 42). According to the Fig. 7B, the MCF-7 multilayer structures had a much higher resistance to GNP penetration as compared to the MDA-MB-231 MCL structure. This variation in NP penetration through MCLs generated from different cell lines could be mainly due to the differences in their ECM as discussed previously. In MDA-MB-231 tissue, NPs were able to penetrate deeper due to breakdown in the ECM matrix. However, MCF-7 tissue had a much more organized ECM and therefore ECM acted as a barrier for NP penetration. 

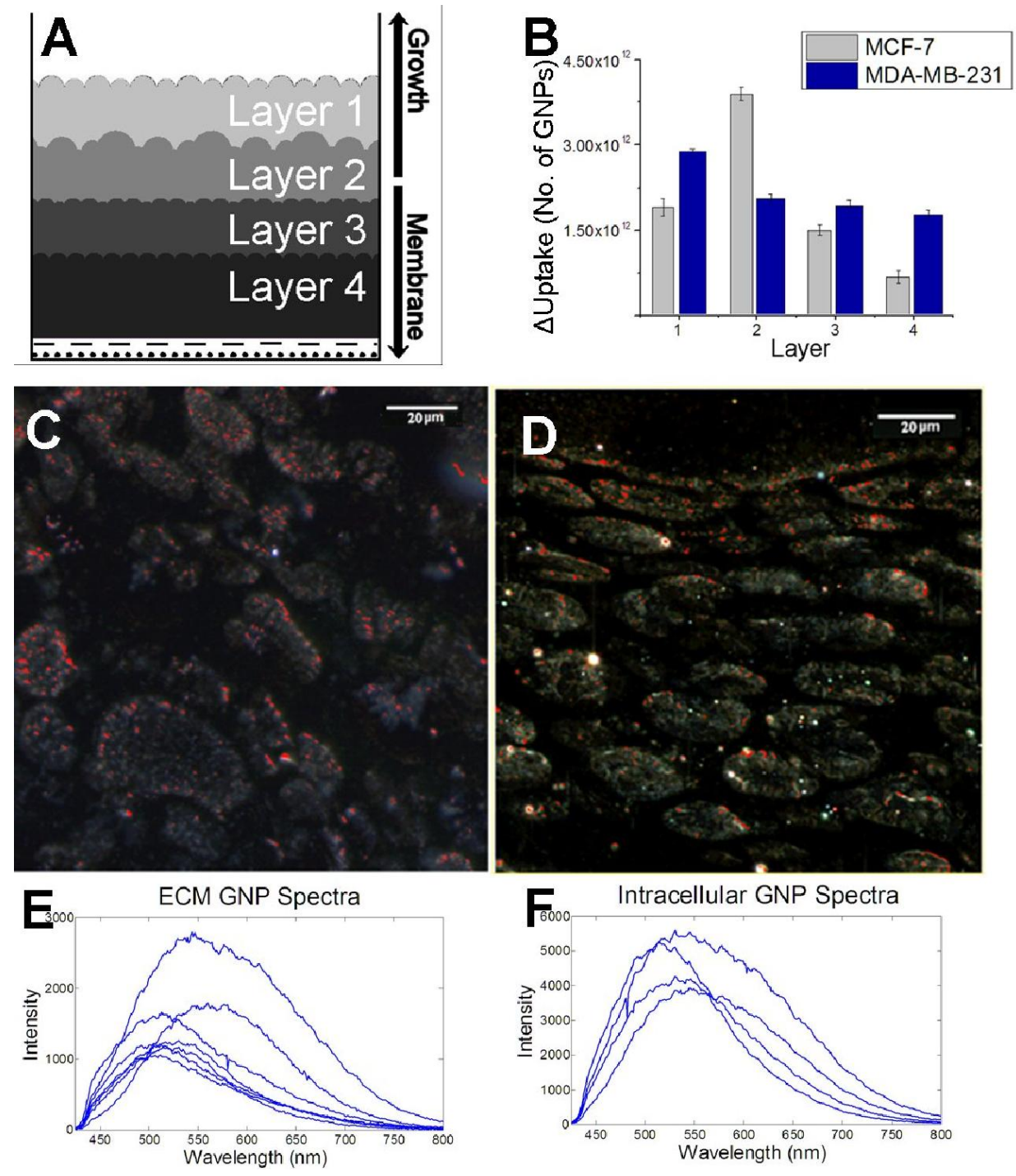

Figure 8: Mapping of NP transport through different layers of a thicker tissue. A, A schematic depicting the multiple layers of a tissue cross-section. B, Accumulation of NPs in different layers of tissue. C-D, Mapping of the NP distribution in MDA-MB-231 and MCF-7 tissue (with GNPs labelled in red), respectively. E-F,A sample of reflectance spectra of GNPs localized in ECM and cells, respectively.Error bars represent the standard deviation and $n=3$.

In the previous section, we discussed the accumulated transport of NPs in tissues with different thickness (Fig. 7). It would be interesting to evaluate the NP transport through different layers of a thicker tissue. We were able to differentiate the NP transport in different layers of a thicker tissue quantitatively and qualitatively (see Fig. 8). According to Fig. 8B, MDA-MB-231 tissue 
has more NP penetration in deeper tissue in contrast to MCF-7. Figure $8 \mathbf{C}$ shows that MDAMB-231 cells were able to access NPs deeper into the tissue. Transport of NPs through MCF-7 tissue is illustrated in Fig. 8D and fewer were found in lower depths of the tissue. This further explains the outcome shown in Fig. 6. Using our CytoViva hyperspectral optical microscope, we looked at the spectral differences between NPs localized within the cell and in ECM. The clustering of NPs in the cells is expected as GNPs are known to be grouped into endosomes upon entry into the cell via receptor-mediated endocytosis $(43,44)$. According to Figures 8 E and F, NPs internalized within the cells have an overall red shift in the spectra as compared to NPs in the ECM. This shows that most of the NPs in the ECM are still not aggregated as compared to the ones within cells. Hence, it is important to optimize the transport of these NPs through ECM in order for them to reach cells effectively. This is the first time NP transport through tissue-like structures is studied using MCL cell models. There is a tremendous effort to incorporate NPs into existing cancer therapeutic protocols. We have demonstrated that MCL models can be used to study the transport of novel NP-based systems to optimize their delivery within tumor tissue. This would accelerate such NP-based innovations into clinics sooner improving the quality of life of cancer patients.

\subsection{4 - Conclusions}

This work demonstrates the importance in understanding the limitations of monolayer cultures in their ability to predict the uptake and effectiveness of cancer treatments in solid tumors. Furthermore, these results underscore the importance of the ECM in terms of transport throughout tumor tissue. By engaging these issues, GNP-based systems can be designed for combined chemoradiation (chemotherapy and radiation therapy) to better overcome the resistance to drugs and radiation found in solid tumors (2). 


\section{References}

1. Lee, J., Chatterjee, L.D.K, Lee, M.H., Krishnan, S. Gold nanoparticles in breast cancer treatment: Promise and potential pitfalls. Cancer Lett., 347: 46-53, 2014.

2. Jelveh, S. and Chithrani, D. B. Gold Nanostructures as a Platform for Combinational Therapy in Future Cancer Therapeutics. Cancers, 3: 1081-1110, 2011.

3. Li, J-L., Wang, W., Liu, X-Y., Zhang, Z-P., Guo, H-C., Liu, W-M., Tang, S-H. In vitro cancer cell imaging and therapy using transferrin-conjugated gold nanoparticles, Recent Cancer Lett., 274: 319-326, 2008.

4. Cuenca, A. G., Jiang, H., Hochwald, S. N., Delano, M., Cance, W. G., and Grobmyer, S. R. Emerging implications of nanotechnology on cancer diagnostics and therapeutics. Cancer, 107: 459-466., 2006.

5. Rao, j. Shedding Light on Tumors Using Nanoparticles. ACS Nano, 2: 1984-1986, 2008.

6. Hauck, T. S., Jennings, J. L., Yatsenko, T., Kumaradas, J. C., and Chan, W. C. W. Enhancing the Toxicity of Cancer Chemotherapeutics with Gold Nanorod Hyperthermia. Adv. Mater., 20: 3832-3838, 2008.

7. Alivisatos, P. The use of nanocrystals in biological detection. Nat. Biotech., 22: 47-51, 2003.

8. Liong, M., Lu, J., Kovochich, M., Xia, T., Ruehm, S. G., Nel, A. E., Tamanoi, F., and Zink, J. I. Multifunctional Inorganic Nanoparticles for Imaging, Targeting, and Drug Delivery. ACS Nano, 2: 889-896, 2008.

9. Langereis, S., Keupp, J., van Velthoven, J. L. J., de Roos, I., H. C., , Burdinski, D., Pikkemaat, J. A., and Gru“, H. A Temperature-Sensitive Liposomal 1H CEST and 19F 
Contrast Agent for MR Image-Guided Drug Delivery. J. Am. Chem. Soc., 9: 1380-1381, 2009.

10. Perrault, S. D., Walkey. C, Jennings. T., Fischer, H. C., and Chan, W. C. W. Mediating Tumor Targeting Efficiency of Nanoparticles Through Design. Nano Lett., 9: 1909-1915, 2009.

11. Lee, J. E., Lee, N., Kim, H., Kim, J., Choi, S. H., Kim, J. H., Kim, T., Song, I. C., Park, S. P., Moon, W. K., and Hyeon, T. Uniform Mesoporous Dye-Doped Silica Nanocrystals for Simultaneous Enhanced Magnetic Resonance Imaging, Fluorescence Imaging, and Drug Delivery. J. Am. Chem. Soc., 132: 552-557, 2010.

12. Brown, S. D., Nativo, P., Smith, J.-A., Stirling, D., Edwards, P. R., Venugopal, B., Flint, D. J., Plumb, J. A., Graham, D., and Wheate, N. J. Gold Nanoparticles for the Improved Anticancer Drug Delivery of the Active Component of Oxaliplatin. J. Am. Chem. Soc., 132: 4678-4684, 2010.

13. Chithrani, B. D., Jelveh, S., Jalali, F., Van Prooijen, M., Allen, C., Bristow, R. G., Hill, R. P., and Jaffray, D. A. Gold Nanoparticles as a Radiation Sensitizer in Cancer Therapy. Radiat. Res., 173: 719-728, 2010.

14. Yohan, D. and Chithrani, B. D. Applications of Nanoparticles in Nanomedicine. Journal of Biomedical Nanotechnology, 10: 2371-2392, 2014.

15. Maeda, H. Macromolecular therapeutics in cancer treatment: The EPR effect and beyond. J Control Rel, 164: 138-144, 2012.

16. Hicks, K. O., Ohms, S. J., van Zijl, P. L., Denny, W. A., Hunter, P. J., and Wilson, W. R. An experimental and mathematical model for the extravascular transport of a DNA intercalator in tumours. Br. J. Cancer, 76: 894-903, 1997. 
17. Wilson, W. R. and Hicks, K. O. Measurement of extravascular drug diffusion in multicellular layers. Br. J. Cancer, 79: 1623-1626, 1999.

18. Tannock, I. F., Lee, C. M., Tunggal, J. K., Cowan, D. S., and Egorin, M. J. Limited penetration of anticancer drugs through tumor tissue: a potential cause of resistance of solid tumors to chemotherapy. Clin. Cancer Res., 8: 878-884, 2002.

19. Cowan, D. S., Hicks, K. O., and Wilson, W. R. Multicellular membranes as an in vitro model for extravascular diffusion in tumours. The British journal of cancer.Supplement, 27: S28-31, 1996.

20. Minchinton, A. I., Wendt, K. R., Clow, K. A., and Fryer, K. H. Multilayers of cells growing on a permeable support. An in vitro tumor model. Acta Oncologica (Stockholm, Sweden), 36: 13-16, 1997.

21. Minchinton, A. I. and Tannock, I. F. Drug penetration in solid tumours. Nat Rev Cancer, 6: 583-592, 2006.

22. Thomlinson, R. H. and Gray, L. H. The histological structure of some human lung cancers and the possible implications for radiotherapy. British journal of cancer, 9: 539$549,1955$.

23. Tannock, I. F. and Hayashi, S. The proliferation of capillary endothelial cells. Cancer research, 32: 77-82, 1972.

24. Denekamp, J. and Hobson, B. Endothelial-cell proliferation in experimental tumours. Br.J. cancer, 46: 711-720, 1982.

25. Netti, P. A., Berk, D. A., Swartz, M. A., Grodzinsky, A. J., and Jain, R. K. Role of extracellular matrix assembly in interstitial transport in solid tumors. Cancer research, 60 : 2497-2503, 2000. 
26. Davies Cde, L., Berk, D. A., Pluen, A., and Jain, R. K. Comparison of IgG diffusion and extracellular matrix composition in rhabdomyosarcomas grown in mice versus in vitro as spheroids reveals the role of host stromal cells. British journal of cancer, 86: 1639-1644, 2002.

27. Brown, E., McKee, T., diTomaso, E., Pluen, A., Seed, B., Boucher, Y., and Jain, R. K. Dynamic imaging of collagen and its modulation in tumors in vivo using secondharmonic generation. Nature medicine, 9: 796-800, 2003.

28. Frens, G. Controlled nucleation for the particle size in monodisperse gold suspensions. Nature, 241: 20-22, 1973.

29. Tennyson, G. S. and Lane, B. P. In vivo and in vitro growth of a rat tracheal squamous cell carcinoma. Cancer research, 41: 4687-4692, 1981.

30. Kovacs, C. J., Evans, M. J., and Hopkins, H. A. Properties of the H-4-II-E tumor cell system. II. In vitro characteristics of an experimental tumor cell line. Cell and tissue kinetics, 10: 245-254, 1977.

31. Rofstad, E. K., Pettersen, E. O., Lindmo, T., and Oftebro, R. THE PROLIFERATION KINETICS OF NHIK 1922 CELLS IN VITRO AND IN SOLID TUMOURS IN ATHYMIC MICE. Cell proliferation, 13: 163-171, 1980.

32. Hicks, K. O., Fleming, Y., Siim, B. G., Koch, C. J., and Wilson, W. R. Extravascular diffusion of tirapazamine: effect of metabolic consumption assessed using the multicellular layer model. International journal of radiation oncology, biology, physics, 42: 641-649, 1998. 
33. Koch, C. J., Kruuv, J., Frey, H. E., and Snyder, R. A. Plateau phase in growth induced by hypoxia. International journal of radiation biology and related studies in physics, chemistry, and medicine, 23: 67-74, 1973.

34. Hirst, D. G. and Denekamp, J. Tumour cell proliferation in relation to the vasculature. Cell and tissue kinetics, 12: 31-42, 1979.

35. Liotta, L. A., Thorgeirsson, U. P., and Garbisa, S. Role of collagenases in tumor cell invasion. Cancer Metast. Rev., 1: 277-288, 1982.

36. Wirl, G. and Frick, J. Collagenase--a marker enzyme in human bladder cancer? Urol.Res., 7: 103-108, 1979.

37. Gross, J. and Nagai, Y. Specific degradation of the collagen molecule by tadpole collagenolytic enzyme. Proc.Natl. Acad. Sci. USA.,54: 1197-1204, 1965.

38. Saltzman, W. M., Radomsky, M. L., Whaley, K. J., and Cone, R. A. Antibody diffusion in human cervical mucus. Biophys. J., 66: 508-515, 1994.

39. Levick, J. R. Flow through interstitium and other fibrous matrices. Quarterly journal of experimental physiology (Cambridge, England), 72: 409-437, 1987.

40. Barocas, V. H. and Tranquillo, R. T. An anisotropic biphasic theory of tissue-equivalent mechanics: the interplay among cell traction, fibrillar network deformation, fibril alignment, and cell contact guidance. Journal of Biomechanical Engineering, 119: 137145, 1997.

41. Primeau, A. J., Rendon, A., Hedley, D., Lilge, L., and Tannock, I. F. The distribution of the anticancer drug Doxorubicin in relation to blood vessels in solid tumors.Clin. Cancer Res., 11: 8782-8788, 2005. 
42. Tannock, I. F. The relation between cell proliferation and the vascular system in a transplanted mouse mammary tumour. Br. J. Cancer, 22: 258-273, 1968.

43. Chithrani, B. D., Ghazani, A. A., and Chan, W. C. Determining the size and shape dependence of gold nanoparticle uptake into mammalian cells. Nanolett.6: 662-668, 2006.

44. Chithrani, B. D. and Chan, W. C. W. Elucidating the Mechanism of Cellular Uptake and Removal of Protein-Coated Gold Nanoparticles of Different Sizes and Shapes. NanoLett., 7: 1542-1550, 2007.

\section{Contributions:}

Darren Yohan: MCL growth, sectioning and imaging; GNP synthesis, characterization, and incubation; analysis of ICP-AES data and results, wrote paper

Charmainne Cruje: ICP-AES data collection and editing of paper

Xiaofeng Lu: Consulted on MCL sectioning/staining procedures

Dr. Devika Chithrani: Editing of paper and help with analysis of results

From: editorial_office@nmletters.org <editorial_office@nmletters.org>

Date: Thu, Apr 30, 2015 at 11:25 AM

Subject: Re: Re: Copyright.com Order Confirmation 313283

To: Devika Chithrani < devika.chithrani@ryerson.ca>

Dear Prof. Devika and Mr. Darren Yohan,

This is a permission given to Mr. Darren Yohan to use his paper ( Elucidating the Uptake and Distribution of Nanoparticles in Solid Tumors via a Multilayered Cell Culture Model, Nano-Micro Letters April 2015, Volume 7, Issue 2, pp 127-137) in his thesis as a chapter.

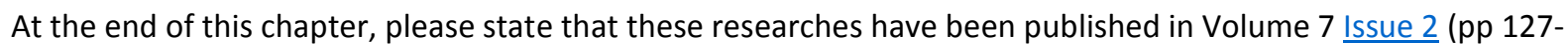
137) of Nano-Micro Letters in April 2015.

Best regards

Dr. Lillian Zhang

Editorial Office, Nano-Micro Letters

This research has been published in Volume 7, Issue 2 (pp. 127-137) of Nano-Micro Letters in April 2015. Reproduced with permission from Springer Group. 


\title{
Multilayer Cell Culture Uptake of $50 \mathrm{~nm}$ Gold Nanoparticles
}

\author{
Darren Yohan \\ Master of Science \\ Biomedical Physics, 2015 \\ Ryerson University
}

\subsection{0 - Abstract}

Gold nanoparticles (GNPs) are a major component of anti-cancer therapeutics. In addition to being used as radiation sensitizers, they have also been employed to increase the efficacy and delivery of photodynamic and photothermal agents as well as chemotherapeutic drugs. However their success depends on their ability to penetrate and distribute homogenously in tumor tissue. In this work, multicellular layers (MCLs) were grown to model the post-vascular tumor environment. GNPs of $20 \mathrm{~nm}$ and $50 \mathrm{~nm}$ diameters were used to discern the effects of size on the GNP penetration and distribution dynamics. Though the GNPs were able to penetrate into the tumor tissue, their penetration was inversely proportional to the GNP size. Similar to in vivo tissue, the MCLs exhibited a much more extensive extracellular matrix (ECM) than monolayer cell cultures. This increased ECM could be the major cause of the size-dependent effects of GNP uptake in tumor tissue. This work highlights the importance of both the improved tissue model provided by MCLs as well as the importance of GNP functionalization in cancer therapeutics. 


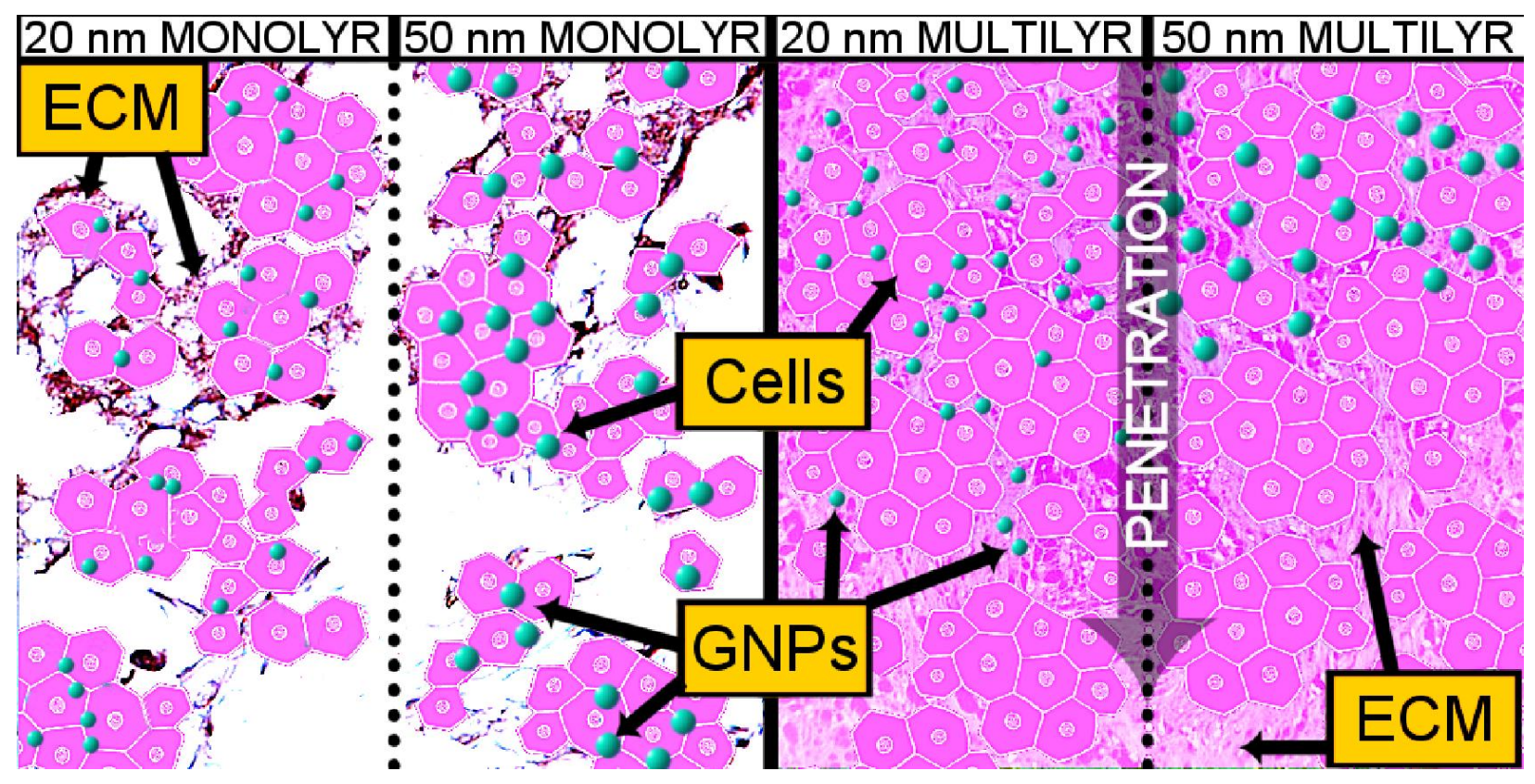

Figure 1: Thematic figure representing the comparison of GNP uptake in monolayer (left) and multilayer cell cultures (right). GNPs spread evenly regardless of size in monolayer cultures and

$50 \mathrm{~nm}$ GNPs have a higher relative uptake per cell. In the MLC $50 \mathrm{~nm}$ GNPs display poorer accumulation and penetration as they wrestle with the prohibitive effects of the ECM.

\subsection{0 - Size Dependence of Gold Nanoparticle Uptake}

Of particular interest to NP research is the size dependence of NP uptake that has been confirmed by a number of independent groups(1-3). It was found that the uptake of GNPs across a variety of cell lines was highest for $50 \mathrm{~nm}$ GNPs and that smaller $(<40 \mathrm{~nm})$ as well as larger $(>80 \mathrm{~nm})$ GNPs had almost a twofold decrease in uptake per cell $(1,4)$.

This thermodynamic model described in section 1.2.1 adequately predicts an optimal GNP size for uptake consistent with the findings by other groups $(5,6)$. However it was shown that the size dependence of GNP uptake may differ between monolayer cultures and solid tumor models that more accurately represent the in vivo tumor environment(7-13). The results from section 2 suggest the possibility that the ECM may play a large role in determining the transport dynamics 
of GNPs. Given that transport through the ECM is diffusion-dependent, there exists at the very least, a competing dynamic that predicts GNP transport to be inversely proportional to GNP size. By comparing the $20 \mathrm{~nm}$ results with a second set of $50 \mathrm{~nm}$ trials, the overall effect might be elucidated. 


\subsection{1 - Size Dependence at the Multilayer Level}

\section{Preliminary Results}

One of the most startling results of monolayer GNP uptake studies was the size-dependence of GNP uptake(1). It was shown by several groups, that $50 \mathrm{~nm}$ GNPs are preferentially taken up by cells as opposed to smaller or larger GNPs(1,5,14-17). This phenomenon is largely explained by the energy interplay between the receptor-ligand binding process and the deformation energy of the cell (see section 1.2.1)(5,6). It was however unknown as to whether or not this effect would carry over into the multilayer model. 

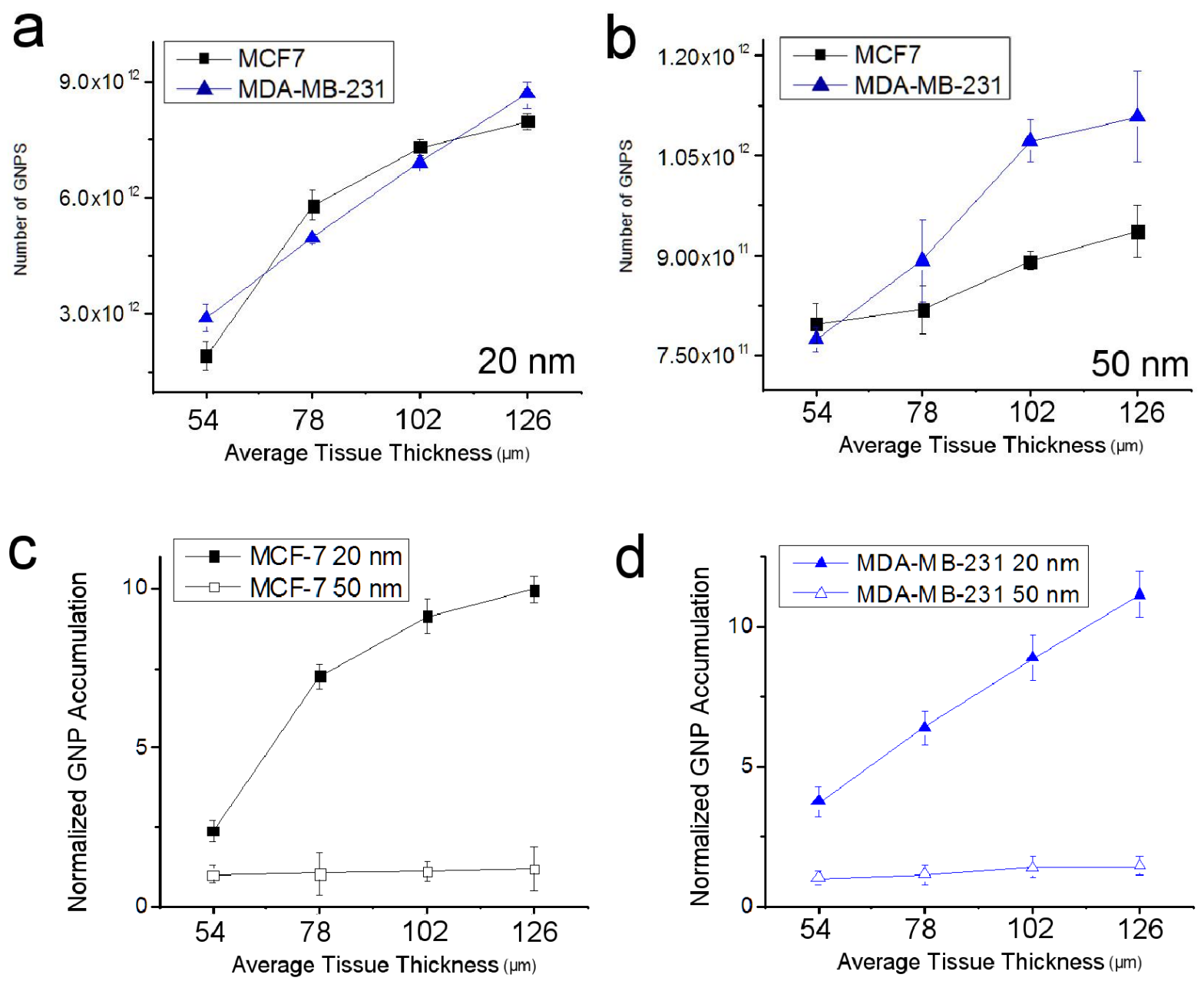

Figure 2: Accumulation of GNPs as a function of tissue thickness for $20 \mathrm{~nm}$ GNPs (a) and $50 \mathrm{~nm}$ GNPs (b). GNP Accumulation for each MCF-7 (c) and MDA-MB-231 (d) normalized to the day $150 \mathrm{GNP}$ sample is also shown.

To test this, $50 \mathrm{~nm}$ GNPs were incubated at the same concentration and for the same time period in MLCs as the $20 \mathrm{~nm}$ GNPs appearing on section 2. The results of these experiments appear in Figure 2. These results suggest that the optimal particle size-dependence of GNP uptake is replaced in the multilayer model by a more linear size-dependence trend. Figure 2 shows that the overall accumulation of GNPs in cells is lower and that the penetration of the larger GNPs is 
much worse than the smaller GNPs. These results further suggest that the ECM plays a larger role in the transport of GNPs through tissue than the individual cells themselves.

Examination of the rate of change in accumulation on consecutive days (Figure 3) provides a qualitative look at the penetration of GNPs in the MLC tissue. For the $20 \mathrm{~nm}$ GNPs in the MDA-MB-231 cells, the rate of change in accumulation appears to be steadier than the MCF-7 cells. With $50 \mathrm{~nm}$ GNPs, the penetration in the MDA-MB-231 cells is much higher than that of MCF-7 cells. This seems to suggest that the diffusive nature of ECM transport is far more pronounced with the $50 \mathrm{~nm}$ GNPs and also highlights the importance of the ECM-limiting effect in the much less structured MDA-MB-231 tissue as opposed to the more ordered and thus more prohibitive MCF-7 tissue. This result is corroborated by several studies that have proposed the effects of collagen content and ECM structure as the major factors in the prohibition of macromolecule penetration through tumor tissue $(7,8,16,18-23)$.
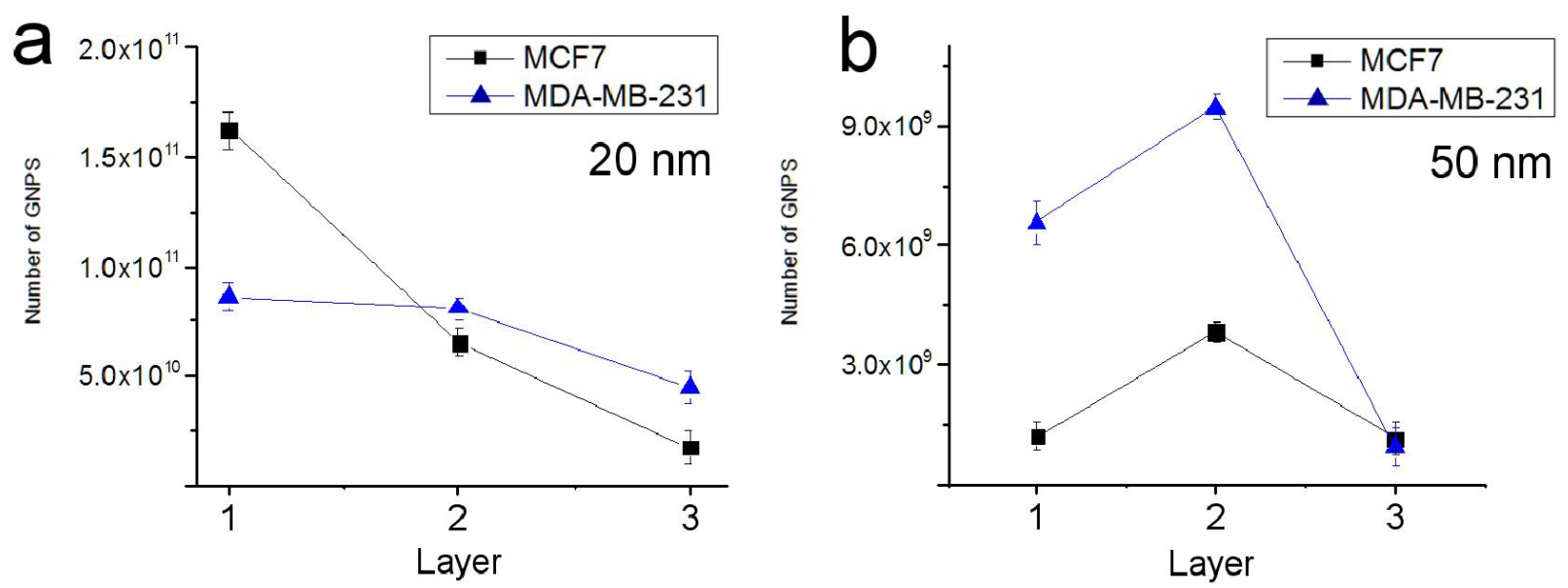

Figure 3: Penetration of GNPs calculated by taking the difference in accumulation on consecutive days of growth. The left group shows the penetration of $20 \mathrm{~nm}$ GNPs as a function of MCL layer and the right shows the penetration of $50 \mathrm{~nm}$ GNPs as a function of layer. 
It is important to note that the penetration of the $50 \mathrm{~nm}$ GNPs diminishes rapidly as the MCL tissue grows from $95-130 \mu \mathrm{m}$ after 24 hours of incubation. While this mimics the results seen in vivo wherein the average uptake of therapeutic agents decreases as tumor weight increases $(21,22)$, the most probable cause differs from the in vivo situation. Solid tumors in vivo exhibit four distinct regions of differing perfusion rates: a necrotic region devoid of vasculature, a semi-necrotic region, a stable microcirculation region and the advancing front of the tumor. These heterogeneities lead to the observed heterogeneous spatial distribution in solid tumors as well as the trend of decreasing uptake with increased tumor weight(21). In the MCL, which is avascular, the trend likely arises from the larger GNPs not having sufficient time to penetrate into the lower areas. These results, though preliminary, further show the importance of the diffusion-limited transport through the ECM which has been shown to be exacerbated both by collagen content and the structural organization of the ECM scaffolds.

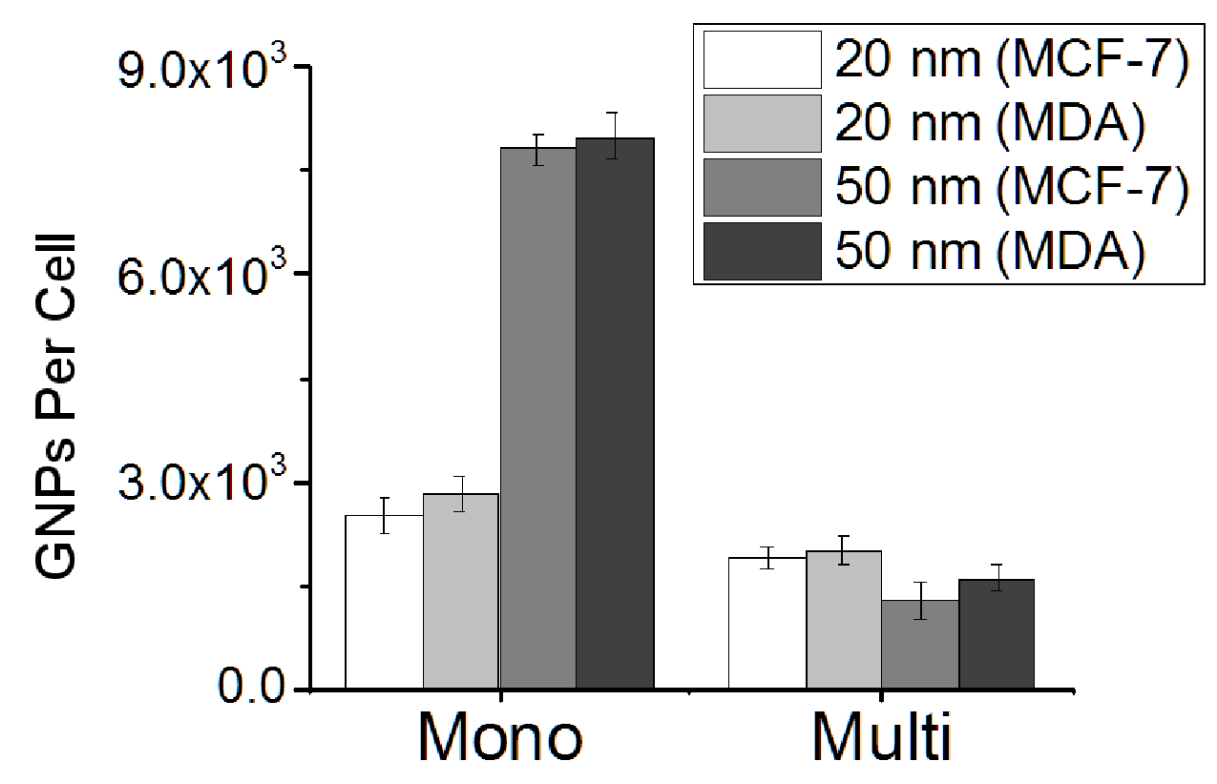

Figure 4: Single day GNP uptake per cell for the monolayer and multilayer cultures across both cell lines for the 20 and $50 \mathrm{~nm}$ GNPs. The difference between the sizes was statistically significant at the $5 \%$ level for the monolayer and multilayer samples. 
Figure 4 depicts the variation in uptake per cell across both cell lines for the 20 and $50 \mathrm{~nm}$ GNPs. The overwhelming increase in uptake at the monolayer level for the $50 \mathrm{~nm}$ particles is reversed at the multilayer level. 


\subsection{2 - Conslusions and Future Work}

If indeed the ECM plays a larger role in GNP transport than the tumor cells themselves, the design of GNPs would benefit from addressing the prohibitive ECM effects more so than the use of ligands that aid the RME process. Such GNP systems could include collagenase coated GNPs(7) or large GNPs that house or disassemble into smaller GNPs. As mentioned in section 1.2.0, the design of GNP systems depends largely on the treatment for which they are being deployed. As such the need for GNPs to be in close proximity to target cells may prohibit such an ECM-centric design. For example, in order for GNPs to enter the nucleus, several ligands must be attached to the surface in order for endosomal escape and nuclear membrane penetration to be achieved(24,25). These ligands take up valuable surface area on the GNP and thus a tradeoff between nuclear entry and tissue penetration would have to be considered. These systems would benefit from the suggestion that GNP systems appear to be more effective penetrators in invasive cell lines as evidenced by these results.

The MLC model provides a much more representative in vivo model than the classic monolayer model. The design of GNP systems has largely rested on achieving better GNP-cell interactions and improving the outcomes of receptor-mediated endocytosis(26-40). This design philosophy ignores the effects of the ECM which has been shown here to potentially be as important a factor in the transport of GNPs in solid tumors as the cells themselves.

In the future, ligand-bound GNP systems can be tested with the MLC model to determine which ligands actively improve the overall accumulation of GNPs at depth in solid tumors. While these trends are suggestive, they must be confirmed by in vivo trials and perhaps the use of more cell lines. In particular, the use of estrogen with MCF-7 has been shown to boost the invasive 
properties of the MCF-7 cell line(41-44). Results using an estrogen-fed MCF-7 multilayer tissue would provide more insight into the mechanics behind the size-dependent trends in uptake of GNPs in MLCs. 


\section{References}

1. Chithrani, B.D., Ghazani, A.A. and Chan, W.C. (2006) Determining the size and shape dependence of gold nanoparticle uptake into mammalian cells. Nano letters, 6, 662-668.

2. Aoyama, Y., Kanamori T Fau - Nakai, T., Nakai T Fau - Sasaki, T., Sasaki T Fau Horiuchi, S., Horiuchi S Fau - Sando, S., Sando S Fau - Niidome, T. and Niidome, T. (2003) Artificial viruses and their application to gene delivery. Size-controlled gene coating with glycocluster nanoparticles. J Am Chem Soc., 125, 3455-3457.

3. Wang, S.H., Lee Cw Fau - Chiou, A., Chiou A Fau - Wei, P.-K. and Wei, P.K. (2010) Size-dependent endocytosis of gold nanoparticles studied by three-dimensional mapping of plasmonic scattering images. J Nanobiotechnology., 8.

4. Chithrani, B.D. and Chan, W.C. (2007) Elucidating the mechanism of cellular uptake and removal of protein-coated gold nanoparticles of different sizes and shapes. Nano letters, $7,1542-1550$.

5. Gao, H., Shi W Fau - Freund, L.B. and Freund, L.B. (2005) Mechanics of receptormediated endocytosis. Proc Natl Acad Sci US A.

6. Zhang, S., Li, J., Lykotrafitis, G., Bao, G. and Suresh, S. (2009) Size-Dependent Endocytosis of Nanoparticles. Advanced materials, 21, 419-424.

7. Goodman, T.T., Olive, P.L. and Pun, S.H. (2007) Increased nanoparticle penetration in collagenase-treated multicellular spheroids. International Journal of Nanomedicine, 2 , $265-274$.

8. Ramanujan, S., Pluen, A., McKee, T.D., Brown, E.B., Boucher, Y. and Jain, R.K. (2002) Diffusion and convection in collagen gels: implications for transport in the tumor interstitium. Biophysical journal, 83, 1650-1660. 
9. Grantab, R., Sivananthan, S. and Tannock, I.F. (2006) The penetration of anticancer drugs through tumor tissue as a function of cellular adhesion and packing density of tumor cells. Cancer Res., 66, 1033-1039.

10. Minchinton, A.I. and Tannock, I.F. (2006) Drug penetration in solid tumours. Nat Rev Cancer, 6, 583-592.

11. Tannock, I.F., Lee, C.M., Tunggal, J.K., Cowan, D.S. and Egorin, M.J. (2002) Limited penetration of anticancer drugs through tumor tissue: a potential cause of resistance of

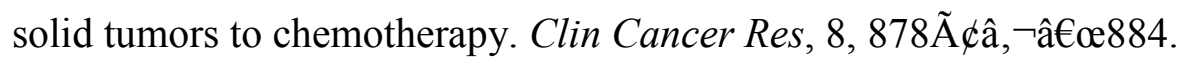

12. Dreher, M.R., Liu W Fau - Michelich, C.R., Michelich Cr Fau - Dewhirst, M.W., Dewhirst Mw Fau - Yuan, F., Yuan F Fau - Chilkoti, A. and Chilkoti, A. (2006) Tumor vascular permeability, accumulation, and penetration of macromolecular drug carriers. $J$ Natl Cancer Inst., 98.

13. Alexandrakis, G., Brown Eb Fau - Tong, R.T., Tong Rt Fau - McKee, T.D., McKee Td Fau - Campbell, R.B., Campbell Rb Fau - Boucher, Y., Boucher Y Fau - Jain, R.K. and Jain, R.K. (2004) Two-photon fluorescence correlation microscopy reveals the two-phase nature of transport in tumors. Nat Med., 10, 203-207.

14. Jin, H., Heller, D.A., Strano, M.S., Sharma, R. and Strano, M.S. (2009) Size-Dependent Cellular Uptake and Expulsion of Single-Walled Carbon Nanotubes: Single Particle Tracking and a Generic Uptake Model for Nanoparticles. ACS Nano, 3, 149-158.

15. Shi, W.W.J.F.X.G.H. (2008) Size and shape effects on diffusion and absorption of colloidal particles near a partially absorbing sphere: Implications for uptake of nanoparticles in animal cells. Phy Rev E, 78, 061914. 
16. Wang, S.H., Lee, C.W., Chiou, A. and Wei, P.K. (2010) Size-dependent endocytosis of gold nanoparticles studied by three-dimensional mapping of plasmonic scattering images. Journal of nanobiotechnology, 8, 33-3155-3158-3133.

17. Zhang, S., Li, J., Lykotrafitis, G., Bao, G. and Suresh, S. (2009) Size-dependent Endocytosis of Nanoparticles. Adv Mater, 21, 419-424.

18. Kuppen, P.J., van der Eb Mm Fau - Jonges, L.E., Jonges Le Fau - Hagenaars, M., Hagenaars M Fau - Hokland, M.E., Hokland Me Fau - Nannmark, U., Nannmark U Fau Goldfarb, R.H., Goldfarb Rh Fau - Basse, P.H., Basse Ph Fau - Fleuren, G.J., Fleuren Gj Fau - Hoeben, R.C., Hoeben Rc Fau - van de Velde, C.J. et al. (2001) Tumor structure and extracellular matrix as a possible barrier for therapeutic approaches using immune cells or adenoviruses in colorectal cancer. Histochem Cell Biol.

19. Liotta, L.A. (1986) Tumor invasion and metastases--role of the extracellular matrix: Rhoads Memorial Award lecture.

20. Netti, P.A., Berk Da Fau - Swartz, M.A., Swartz Ma Fau - Grodzinsky, A.J., Grodzinsky Aj Fau - Jain, R.K. and Jain, R.K. (2000) Role of extracellular matrix assembly in interstitial transport in solid tumors.

21. Jain, R.K. (1999) Transport of molecules, particles, and cells in solid tumors. Annual Review of Biomedical Engineering, 1, 241-263.

22. Jain, R.K. (2001) Delivery of molecular and cellular medicine to solid tumors. Adv Drug Deliv Rev. .

23. Stylianopoulos, T., Poh, M.Z., Insin, N., Bawendi, M.G., Fukumura, D., Munn, L.L. and Jain, R.K. (2010) Diffusion of particles in the extracellular matrix: the effect of repulsive electrostatic interactions. Biophysical journal, 99, 1342-1349. 
24. Yang, C., Neshatian, M., Van Prooijen, M. and Chithrani, B.D. (2013) Enhanced cancer therapeutics using peptide-modified gold nanoparticles. ACS Nano, 14, 4813-4819.

25. Yang, C., Uertz J Fau - Yohan, D., Yohan D Fau - Chithrani, B.D. and Chithrani, B.D. (2014) Peptide modified gold nanoparticles for improved cellular uptake, nuclear transport, and intracellular retention. Nanoscale.

26. Anshup, Venkataraman, J.S., Subramaniam, C., Kumar, R.R., Priya, S., Kumar, T.R.S., Omkumar, R.V., John, A. and Pradeep, T. (2005) Growth of gold nanoparticles in human cells. Langmuir, 21, 11562-11567.

27. Bindhani, B.K., Parida, U.K., Biswal, S.K., Panigrahi, A.K. and Nayak, P.L. (2013) Gold Nanoparticles and Their Biomedical Applications. Rev. Nanosci. Nanotechnol., 2, 247260.

28. Brown, S.D., Nativo, P., Smith, J.A., Stirling, D., Edwards, P.R., Venugopal, B., Flint, D.J., Plumb, J.A., Graham, D. and Wheate, N.J. (2010) Gold Nanoparticles for the Improved Anticancer Drug Delivery of the Active Component of Oxaliplatin. J. Am. Chem. Soc., 132, 4678-4684.

29. Cheng, Y., C. Samia, A., Meyers, J.D., Panagopoulos, I., Fei, B. and Burda, C. (2008) Highly efficient drug delivery with gold nanoparticle vectors for in vivo photodynamic therapy of cancer. Journal of the American Chemical Society, 130, 10643-10647.

30. Chithrani, D.B. (2011) Optimization of Bio-Nano Interface Using Gold Nanostructures as a Model Nanoparticle System. Insciences Organisation, 1, 115.

31. Duncan, B., Kim, C. and Rotello, V.M. (2010) Gold nanoparticle platforms as drug and biomacromolecule delivery systems. Journal of Controlled Release, 148, 122-127. 
32. Dykman, L. and Khlebtsov, N. (2012) Gold nanoparticles in biomedical applications: recent advances and perspectives. Chemical Society Reviews, 41, 2256-2282.

33. Gong, T., Olivo, M., Dinish, U.S., Goh, D., Kong, K.V. and Yong, K.T. (2013) Engineering bioconjugated gold nanospheres and gold nanorods as label-free plasmon scattering probes for ultrasensitive multiplex dark-field imaging of cancer cells. Journal of biomedical nanotechnology, 9, 985-991.

34. Han, G., Ghosh, P., De, M. and Rotello, V.M. (2007) Drug and gene delivery using gold nanoparticles. NanoBioTechnology, 3, 40-45.

35. Huang, H.-C., Ramos, J., Grandhi, T.S.P., Potta, T. and Rege, K. (2010) Gold Nanoparticles In Cancer Imaging and Therapeutics. Nano LIFE, 01, 289-307.

36. Hutter, E. and Maysinger, D. (2013) Gold-nanoparticle-based biosensors for detection of enzyme activity. Trends in pharmacological sciences, 34, 497-507.

37. Liang, M., Lin, I.C., Whittaker, M.R., Minchin, R.F., Monteiro, M.J. and Toth, I. (2010) Cellular Uptake of Densely Packed Polymer Coatings on Gold Nanoparticles. ACS Nano, 4, 403-413.

38. Nativo, P., Prior, I.A. and Brust, M. (2008) Uptake and Intracellular Fate of SurfaceModified Gold Nanoparticles. ACS Nano, 2, 1639-1644.

39. Shan, Y., Luo, T., Peng, C., Sheng, R., Cao, A., Cao, X., Shen, M., Guo, R., Tomas, H. and Shi, X. (2012) Gene delivery using dendrimer-entrapped gold nanoparticles as nonviral vectors. Biomaterials, 33, 3025-3035.

40. Wang, Z., Jia, L. and Li, M.H. (2013) Gold nanoparticles decorated by amphiphilic block copolymer as efficient system for drug delivery. Journal of biomedical nanotechnology, 9, 61-68. 
41. Bursch, W., Ellinger A Fau - Kienzl, H., Kienzl H Fau - Torok, L., Torok L Fau Pandey, S., Pandey S Fau - Sikorska, M., Sikorska M Fau - Walker, R., Walker R Fau Hermann, R.S. and Hermann, R.S. (1996) Active cell death induced by the anti-estrogens tamoxifen and ICI 164384 in human mammary carcinoma cells (MCF-7) in culture: the role of autophagy.

42. Hsieh, C.Y., Santell Rc Fau - Haslam, S.Z., Haslam Sz Fau - Helferich, W.G. and Helferich, W.G. (1998) Estrogenic effects of genistein on the growth of estrogen receptor-positive human breast cancer (MCF-7) cells in vitro and in vivo.

43. Wang, T.T. and Phang, J.M. (1995) Effects of estrogen on apoptotic pathways in human breast cancer cell line MCF-7.

44. Wu, L. and Tannock, I.F. (2005) Effect of the selective estrogen receptor modulator arzoxifene on repopulation of hormone-responsive breast cancer xenografts between courses of chemotherapy. Clin Cancer Res, 11, 8195-8200. 